\title{
Article
}

\section{Heat exchanger network optimization for multiple period operations}

\author{
Camila B. Miranda, Caliane Bastos Borba Costa, Jose Antonio Caballero, and Mauro A. S.S. Ravagnani
}

Ind. Eng. Chem. Res., Just Accepted Manuscript • DOI: 10.1021/acs.iecr.6b01117 • Publication Date (Web): 31 Aug 2016

Downloaded from http://pubs.acs.org on September 9, 2016

\section{Just Accepted}

"Just Accepted" manuscripts have been peer-reviewed and accepted for publication. They are posted online prior to technical editing, formatting for publication and author proofing. The American Chemical Society provides "Just Accepted" as a free service to the research community to expedite the dissemination of scientific material as soon as possible after acceptance. "Just Accepted" manuscripts appear in full in PDF format accompanied by an HTML abstract. "Just Accepted" manuscripts have been fully peer reviewed, but should not be considered the official version of record. They are accessible to all readers and citable by the Digital Object Identifier (DOI@). "Just Accepted" is an optional service offered to authors. Therefore, the "Just Accepted" Web site may not include all articles that will be published in the journal. After a manuscript is technically edited and formatted, it will be removed from the "Just Accepted" Web site and published as an ASAP article. Note that technical editing may introduce minor changes to the manuscript text and/or graphics which could affect content, and all legal disclaimers and ethical guidelines that apply to the journal pertain. ACS cannot be held responsible for errors or consequences arising from the use of information contained in these "Just Accepted" manuscripts. 
Heat exchanger network optimization for multiple period operations

\author{
Camila B. Miranda ${ }^{1}$, Caliane B. B. Costa ${ }^{1}$, Jose A. Caballero ${ }^{2}$, Mauro A. S. S. \\ Ravagnani ${ }^{1 *}$ \\ ${ }^{1}$ Chemical Engineering Department, State University of Maringá \\ Av. Colombo 5790, CEP 87020900, Maringá - PR - Brazil \\ ${ }^{2}$ Chemical Engineering Department, University of Alicante \\ Carretera de San Vicente del Raspeig S/N, 03690 - San Vicente del Raspeig - \\ Alicante - Spain \\ *corresponding author: massravagnani@uem.br
}

\begin{abstract}
In this paper an optimization model is presented for the synthesis of a heat exchanger network (HEN) for multi-period operations. A literature very well-known stagewise superstructure is used, but isothermal mixing assumption is not made and a timesharing procedure is adopted. A MINLP problem is solved separately for each period of operation. The final multi-period HEN is synthesized automatically considering the greatest areas and not fixing matches in each device in different periods, which avoids excessive heat exchange areas. Heat exchangers are designed to be feasible in practice, with a minimum acceptable area. Three literature problems were used to test the applicability of the proposed model. The objective function aims to minimize the total annualized cost (TAC). During the implementation of the model, inconsistencies found in the literature were corrected. Results indicate that lower TACs were obtained in the present paper and each heat transfer device is feasible in practice.
\end{abstract}


Keywords: Multi-period heat exchanger networks, optimization, MINLP, multiple periods of operation.

\section{Introduction}

Heat exchangers are used in industrial processes in order to provide cooling and heating of process streams. The set of heat exchangers can be arranged into a network, called a heat exchanger network (HEN). Besides process streams, cold and hot utilities such as cooling water and steam can participate in the streams that exchange energy, in order to meet energy loads.

In addition to incurring costs, the consumption of utilities can also generate effluents that require treatment. Excessive use of hot and cold utilities should therefore be avoided in order to alleviate operating and environmental costs. A manner of achieving this is to recover energy from the process itself, using heat exchangers. Nevertheless, a greater number of heat exchangers means increased capital costs. In order to minimize the total annualized cost (TAC), a tradeoff between energy consumption and capital costs needs to be found, and the task of choosing which process streams should be combined to meet the specified goal is not trivial. Many problem formulations addressing this issue have been described in the literature.

Among the methods used for HEN synthesis, pinch analysis, which uses thermodynamic concepts and heuristic rules, is probably the most popular. Mathematical programming techniques are also often used, and are generally posed as mixed integer nonlinear programming (MINLP) problems, which are solved simultaneously. Alternatively, the problem can be subdivided into independent subproblems, which are sequentially solved so that the solution of a preceding problem serves as an input for the next one. This procedure is used to solve linear programming (LP), mixed integer linear programming (MILP), and nonlinear programming (NLP) 
problems. Such decomposition is advisable when the MINLP problem exhibits high levels of nonconvexities and nonlinear features. Computational difficulties are generally not large. Nevertheless, when the problem is not convex, the solution can become trapped in local optima. In turn, a simultaneous method enables a HEN to be obtained in a direct way, without problem decomposition, simultaneously optimizing all the variables present in the model. The weakness of possibly becoming stuck in local optima still remains, however, depending on the degree of nonlinearity and nonconvexity. Nonetheless, the results are generally better than those obtained by the sequential methods, because all the variables are optimized at the same time. This can be due to the fact that a non-optimal solution found in a step of the sequential procedure will be used as the input in the following step, so the global optimum will not be found. Alternatively, optimization methods based on natural algorithms, such as particle swarm optimization and genetic algorithms can also be used to solve the MINLP problem. These algorithms can avoid becoming trapped in local optima and can achieve near-optimum values. However, there is no effective proof of convergence to a global optimum. Finally, it is also possible to combine two or more of these methods, giving rise to hybrid techniques.

Synthesis of HENs using mathematical programming, instead of pinch analysis, makes it possible to take safety and controllability criteria into consideration, as well as designer preferences, because there is no use of heuristics. Furthermore, HENs can be formulated in a systematic manner, with inclusion of different types of hot and cold utilities and the addition of new constraints. Examples of the latter are the prohibition of heat exchange between two streams for reasons of safety or distance (which might require additional piping and auxiliary valves), or limits on the size (area) of the heat exchangers.

Chemical processes, however, may be multi-period, due to changes in operating conditions or in product recipes, which implies changes in supply or target 
temperatures, heat capacities, or flow rates. The HEN must be robust in order to be able to adapt to multi-period operations, and the synthesis of such a HEN is not a simple task.

The present paper uses the procedure proposed by Jiang and Chang ${ }^{1}$ for the synthesis of heat exchanger networks for multiple periods of operation. The problem has MINLP formulation, and the main objective is to minimize the total annualized cost (TAC). It is worth mentioning that the TAC is actually an expected value, since the HEN is to be used in multiple periods. In the procedure, a HEN is synthesized separately for each period, and an automatic algorithm procedure is used to generate the multi-period HEN, considering the greatest areas and not establishing matches in each heat exchanger in different periods, i.e., the stream matches are not necessarily the same in each heat exchanger in the different periods. This procedure avoids excessive heat exchange areas in each period. In the present study, during the stages temperature calculation, mixing is not restricted to streams of same temperature (isothermal mixing). To avoid results mathematically correct but infeasible to be designed and built in practice, heat exchangers are constrained to exhibit an area at least of $1.0 \mathrm{~m}^{2}$. The developed optimization model corrects inconsistencies in the Jiang and Chang ${ }^{1}$ model, as will be discussed in the case studies section.

\section{Literature review}

In the published studies, HEN synthesis is usually treated as an optimization problem for the minimization of TAC, and is solved by mathematical programming. However, the pioneering works on multi-period HENs were based on pinch analysis. Linnhoff and Kotjabasakis ${ }^{2}$ introduced the concept of downstream paths, aiming to identify the effect of a disturbance on a controlled variable. A simultaneous base case design procedure was also suggested, considering features such as optimization and operability. A methodology for synthesizing a flexible HEN was proposed by 
Kotjabasakis and Linnhoff ${ }^{3}$, in which sensitivity tables are used to achieve a trade-off among energy, capital cost, and flexibility, in order to modify a base case, formulated with pinch analysis for one period. The concept of downstream paths and sensitivity tables were used by Kotjabasakis ${ }^{4}$ to synthesize multi-period HENs, and a strategy was presented to reduce the cost of fouling in HENs. Ravagnani and Módenes ${ }^{5}$ also used the concept of downstream paths to synthesize multi-period HENs.

The first reported study of the synthesis of flexible HENs using mathematical programming was that of Floudas and Grossmann ${ }^{6}$, which considered pre-specified changes in flow rates and in supply and target temperatures during finite periods. A sequential procedure used two criteria: minimum utility costs for each period, and minimum number of heat exchange units. The first criterion was achieved with an extension of the linear programming (LP) model of Papoulias and Grossmann ${ }^{7}$, solved separately for each period. For the second criterion, a multi-period version of the MILP model of Papoulias and Grossmann ${ }^{7}$ was used, taking into account the variations in the pinch point and in the utilities demand in each period. In an extension of that work, based on the nonlinear program (NLP) model of Floudas and co-workers ${ }^{8}$, Floudas and Grossmann ${ }^{9}$ presented a method for the automatic generation of HENs for multi-period operations. A superstructure was presented that included all possible alternatives for a set of pre-specified exchangers, for the different periods. Furthermore, graphs representation was proposed with the aim of reducing the size of the nonlinear problem and considering changes in the pinch point. In the same year, Floudas and Grossmann ${ }^{10}$ presented a systematic method for the synthesis of HENs with specified variations in uncertain parameters. This was based on decomposition into two stages in which flexibility analyses were performed in order to test the operational viability.

Cerdá and co-workers ${ }^{11}$ applied mixed integer linear programming (MILP) to a new version of the energy cascade, with the aim of recovering heat and taking account of transient and permanent process streams. The cascade assumed a continuous 
pinch and established targets for heat recovery and the main pinch temperatures, limiting heat exchanges and dividing the problem into parts, with a HEN synthesized for each part. Cerdá and Galli ${ }^{12}$ added further features to the model of Cerdá and coworkers $^{11}$, in order to solve nonconvex problems and take account of large disturbances in temperatures. These new features made it possible to identify the pinch-jump and evaluate intermediate temperatures at which discontinuity appeared. In turn, the model of Cerdá and Galli ${ }^{12}$ was used by Galli and Cerdá ${ }^{13}$ in a four-step sequential algorithmic approach for the synthesis of flexible HENs.

Papalexandri and Pistikopoulos ${ }^{14,15}$ also studied the synthesis of flexible HENs and developed an efficient MINLP model for this purpose. The synthesis of a flexible mass transfer equipment network was also described by Papalexandri and Pistikopoulos ${ }^{15}$, in order to deal with changes in the temperature, composition, and mass flow rate of process streams.

Aguilera and Nasini ${ }^{16}$ presented a MILP model to test the flexibility of HENs. However, the model only considered cases with variations in the heat capacity of the streams, and temperature variations were not considered. A real-time optimization method for the study of HEN controllability was proposed by Aguilera and Marchetti ${ }^{17}$, using either an LP or an NLP model, depending on whether the stream splitters were used as manipulated variables.

Aaltola ${ }^{18}$ proposed a simultaneous optimization model based on mathematical programming that was able to generate a flexible HEN in a single stage. The model combined a multi-periodic MINLP model and algorithms to optimize the global annual cost. The superstructure used was based on the proposal of Yee and Grossmann ${ }^{19}$ for fixed operating conditions, considering a trade-off between energy and heat transfer area, since an MINLP model simultaneously optimizes utility costs, the number of heat exchange units, and the selection of pairs. The superstructure of Yee and Grossmann $^{19}$, first introduced by Yee and co-workers ${ }^{20}$, was based on a representation 
in stages, divided by temperatures. In each stage, there was the possibility of matches between all hot and all cold streams. Isothermal mixing was assumed for every stream that was divided, which simplified the feasible space because it was only delimited by linear constraints. Yee and Grossmann ${ }^{19}$ did not assume a fixed value for the minimum approach temperature $\left(\Delta T_{\min }\right)$, which was treated as one of the optimization variables. In this model, the problem was not divided into parts from the pinch point. Aaltola ${ }^{18}$ considered the average equipment area in different periods in the objective function. Adjoining algorithms use a NLP/LP model to minimize utility costs.

Konukman and co-workers ${ }^{21}$ also proposed a simultaneous optimization model for the synthesis of a flexible HEN. The model used a non-iterative MILP simultaneous formulation in a superstructure that generated a HEN with the minimum utilities demand and the desired operational flexibility.

Chen and co-workers ${ }^{22}$ improved the methodology proposed by Chen and Hung $^{23}$. Isothermal mixing was not considered, and the area of the equipment was included in the flexibility study. The model proposed simultaneous optimization of the HEN, allowing pre-defined disturbances in temperatures and stream flow rates. The problem was decomposed into stages, considering the synthesis of a candidate HEN, tests of flexibility in the HEN, and the use of integer cuts to eliminate undesired HEN configurations.

Verheyen and Zhang $^{24}$ presented a critical comparative study of the existing HEN synthesis methods. A methodology was then proposed for the synthesis of a flexible HEN, considering multiple periods of operation for a given HEN. This involved a modification of the Aaltola ${ }^{18}$ model and included a NLP model considering nonisothermal mixing. The model used the cost objective function value obtained using, for each piece of equipment, the maximum heat exchange area among all the periods.

Chen and $\mathrm{Hung}^{25}$ extended the work presented in Chen and $\mathrm{Hung}^{23}$, considering known disturbances in temperatures and flow rates in the synthesis of 
flexible HENs, as well as the synthesis of mass exchange networks with known disturbances in the inlet compositions of the streams.

Isafiade and Fraser $^{26}$ presented a MINLP model for HEN synthesis using a superstructure divided into temperature intervals. The construction of this superstructure, called IBMS (Interval Based MINLP Superstructure) by the authors, considered stream splitting in the case of hot streams, according to the inlet and outlet temperatures for each stream. In this scheme, in one temperature interval one hot stream could be represented by only one stream, while in another temperature interval it could be divided into branches, depending on the temperatures. Cold streams were present in all intervals where there was hot stream splitting. Isafiade and Fraser $^{27}$ presented a model for the synthesis of multi-period HENs, based on the IBMS superstructure. The proposal of Verheyen and $\mathrm{Zhang}^{24}$ to use the maximum area in each period was included in the objective function to ensure that the same matching between two streams that exchanged heat in two or more distinct periods could apply to all periods.

In the work of El-Temtamy and $\mathrm{Gabr}^{28}$, LP and MILP models were presented for the identification of flexible HEN configurations with the minimum amount of equipment. The HEN remained flexible to ensure that energy demands in each period of operation were minimized.

Escobar and co-workers ${ }^{29}$ proposed a procedure for the synthesis of a flexible and controllable HEN, based on a decomposition strategy with two steps. The design variables were selected in the first step, and in the second step the control variables were adjusted according to uncertainty parameters. This resulted in a HEN design in which the same control system could be used under different operating conditions, and ensured that the streams achieved the desired temperatures with optimal heat integration.

Jiang and Chang $^{1}$ presented a procedure for the synthesis of flexible multiperiod HEN that used timesharing mechanisms. The main objective of the model was 
to present a different approach for generating multi-period HENs, which does not present some of the drawbacks previous multi-period HENs generation proposals do, such as assuming fixed durations of the periods, which is inevitably not true in real operations, since production schedule has to be adjusted to changes in supplies, demand and/or process conditions. The proposed approach, besides not depending on fixed durations of the different periods (being therefore flexible for unforeseen changes in period durations), also avoided excessive heat exchange areas during periods with much smaller heat duties, and decreased the complexity of the simultaneous optimization models. In such approach, a MINLP model was first used to find the optimal design (the one that minimizes TAC) for each period separately. A timesharing strategy was then applied to integrate all the designs, aiming to reduce the capital cost and maintain the utilities demand at the minimum levels in each period. Although the interesting approach introduced by the authors, who worked with the non-isothermal mixing version of the superstructure model of Yee and Grossmann ${ }^{19}$ for the synthesis of the HEN for each period, they did not adequately implement the model in their work, since some heat exchangers violate the Second Law of Thermodynamics or have wrong calculated areas.

Isafiade and co-workers ${ }^{30}$ presented a modified version of the Yee and Grossmann $^{19}$ superstructure for the synthesis of HENs with multiple periods of operation. The proposed technique consisted of a sequential two-step approach and a set of MINLP models.

Non-deterministic optimization methods have also been used to synthesize flexible or multi-period HENs. Ma and co-workers ${ }^{31,32}$, Xiao and co-workers ${ }^{33}$, Ahmad and co-workers ${ }^{34}$, and $\mathrm{Yi}$ and co-workers ${ }^{35}$ provide examples of this approach, with genetic algorithms (GA) and simulated annealing (SA) being used in different ways.

Nemet and co-workers ${ }^{36}$ presented a stochastic multi-periodic optimization procedure with a MINLP formulation for the design of a HEN, including its life expectancy and fluctuations in energy prices. The objective function considered a 
trade-off between investment and operating costs. The results showed that it was possible to obtain designs with improved economic performance in terms of the TAC.

$\mathrm{Li}$ and co-workers ${ }^{37}$ presented a sequential two-step approach for the synthesis of flexible HENs, which included nonconvex problems. In the first step, the HEN structure was synthesized, and the area was optimized in the second step. The direction matrix method was used to provide flexibility and ensure that the HEN satisfied critical operational criteria.

\section{Model development}

The present paper proposes an optimization model able to obtain a feasible HEN for each period of operation with its associated utilities demand and capital costs. The main objective is to reduce capital costs and to maintain the hot and cold utilities demands at minimum levels, so changes both in process streams parameters and in duration of the different periods can be properly addressed. The Yee and Grossmann ${ }^{19}$ superstructure is used, but without considering isothermal mixing. In this way, the calculation of temperature difference between streams at each end of heat exchanger is made with inlet and outlet temperatures, not with stage temperatures. Furthermore, heat exchangers are designed to be feasible in practice, with a minimum acceptable area $\left(1.0 \mathrm{~m}^{2}\right)$.

As proposed by Jiang and Chang ${ }^{1}$, to decrease the inherent complexity of simultaneously synthesizing the HENs for all periods, an MINLP model is solved for each period separately. The computational procedure (timesharing by Jiang and Chang $^{1}$ ) is used for automatic integration of the HENs obtained in a finite number of periods. The procedure builds multi-period HENs according to the individual areas calculated for each period separately, and does not assume each piece of equipment to have the same matching of streams in all periods, hence avoiding excessive heat exchange areas in each period. 
As simplifying hypothesis, it is assumed that the enthalpy of the process streams depends linearly on the temperature, and that the dynamic effects of disturbances in the inlet and outlet temperatures and the flow rates, from one period to another, can be neglected.

The input data (parameters) that must be known are as follows: hot stream inlet and outlet temperatures; cold stream inlet and outlet temperatures; hot utility inlet and outlet temperatures; cold utility inlet and outlet temperatures; hot and cold stream heat capacities; hot and cold utility costs; hot and cold streams and utilities convective heat transfer coefficients or global heat transfer coefficients; capital cost equation coefficients; annual conversion factor; and heat exchanger minimum approach temperature. The present paper does not assume a fixed value for the minimum temperature difference in each end of heat exchangers, which is treated as one of the optimization variables.

The model uses the approach proposed by $\mathrm{Chen}^{38}$ to calculate the logarithmic mean temperature difference (LMTD). All indexes and parameters, as well as real and integer variables of the model are presented in the Nomenclature section.

If the convective heat transfer coefficients for individual streams $\left(h h_{i}, h c_{j}, h s_{m}\right.$, $\left.h w_{n}\right)$ are available, instead of the global heat transfer coefficients $\left(\operatorname{Co}_{i, j}, \operatorname{Cos}_{m, j}, \operatorname{Cow}_{i, n}\right)$, the latter is calculated with Eq. 1 - 3

$$
\begin{aligned}
& \frac{1}{\operatorname{Co}_{i, j}}=\frac{1}{h h_{i}}+\frac{1}{h c_{j}} \\
& \frac{1}{\operatorname{Cos}_{m, j}}=\frac{1}{h s_{m}}+\frac{1}{h c_{j}} \\
& \frac{1}{\operatorname{Cow}_{i, n}}=\frac{1}{h h_{i}}+\frac{1}{h w_{n}}
\end{aligned}
$$

The objective function to be minimized is the TAC (Eq. 4), where $r$ is the annualizing factor; $a$ is the cost coefficient used to evaluate the fixed capital costs of a heat exchanger; $b$ is the variable capital cost coefficient; and $c$ is heat exchanger area exponent. Binary variables $y_{i, j, k}, y s_{m, j}$ and $y w_{i, n}$ are used to indicate if the heat 
exchangers are present or not in the network and real variables $\operatorname{area}_{i, j, k}, \operatorname{areas}_{m, j}$ and areaw $_{i, n}$ store the heat-transfer areas. The model constraints are the global energy balance for each process stream; the energy balance in each stage; the energy balance in each heat exchanger; the summation of the stream splitting fractions; the outlet temperatures of the streams from the different items of equipment; the temperature feasibility calculation; the utility heat duties; the logical constraints on the heat exchanged; and the design of the heat exchangers.

The model can be described as:

$$
\begin{aligned}
& \min \mathrm{TAC}=\sum_{i} \sum_{j} \sum_{k}\left[r \cdot a \cdot y_{i, j, k}+r \cdot b \cdot\left(\text { area }_{i, j, k}\right)^{c}\right]+\sum_{m} \sum_{j}\left[r \cdot a \cdot y s_{m, j}+r \cdot b \cdot\right. \\
& \left.\left(\text { areas }_{m, j}\right)^{c}\right]+\sum_{i} \sum_{n}\left[r \cdot a \cdot y w_{i, n}+r \cdot b \cdot\left(\text { areaw }_{i, n}\right)^{c}\right]+\left(\sum_{m} \sum_{j} C_{m} \cdot q s_{m, j}\right)+ \\
& \left(\sum_{i} \sum_{n} C_{n} \cdot q w_{i, n}\right)
\end{aligned}
$$

Subject to:

Energy balance for each stream:

$$
\begin{aligned}
& \left(\text { Thin }_{i}-\text { Thout }_{i}\right) \cdot F h_{i}=\left(\sum_{k} \sum_{j} q_{i, j, k}\right)+\left(\sum_{n} q w_{i, n}\right) \\
& \left(\text { Tcout }_{j}-\text { Tcin }_{j}\right) \cdot F c_{j}=\left(\sum_{k} \sum_{i} q_{i, j, k}\right)+\left(\sum_{m} q s_{m, j}\right)
\end{aligned}
$$

Energy balance for each stage of the superstructure:

$$
\begin{aligned}
& \left(t h_{i, k}-t h_{i, k+1}\right) \cdot F h_{i}=\sum_{j} q_{i, j, k} \\
& \left(t c_{j, k}-t c_{j, k+1}\right) \cdot F c_{j}=\sum_{i} q_{i, j, k}
\end{aligned}
$$

Energy balance for each heat exchanger:

$$
\begin{aligned}
& \left(t h_{i, k}-t h s_{i, j, k}\right) \cdot r h_{i, j, k} \cdot F h_{i}=q_{i, j, k} \\
& \left(t c s_{i, j, k}-t c_{j, k+1}\right) \cdot r c_{i, j, k} \cdot F c_{j}=q_{i, j, k}
\end{aligned}
$$

Summation of stream fractions due to stream splitting:

$$
\begin{aligned}
& \sum_{j} r h_{i, j, k}=1.0 \\
& \sum_{i} r c_{i, j, k}=1.0
\end{aligned}
$$

Mixer energy balance:

$\sum_{j}\left(r h_{i, j, k} \cdot t h s_{i, j, k}\right)=t h_{i, k+1}$ 


$$
\sum_{i}\left(r c_{i, j, k} \cdot t c s_{i, j, k}\right)=t c_{j, k}
$$

Temperature feasibility:

$$
t h_{i, 1}=\operatorname{Thin}_{i}
$$

$t c_{j, N O K+1}=\operatorname{Tcin}_{j}$

$$
t h_{i, k} \geq t h_{i, k+1}
$$

$$
t c_{j, k} \geq t c_{j, k+1}
$$

$$
t h_{i, N O K+1} \geq \text { Thout }_{i}
$$

$$
t c_{i, 1} \leq \text { Tcout }_{j}
$$

Utility demands:

$$
\begin{aligned}
& \left(t h_{i, N O K+1}-\text { Thout }_{i}\right) \cdot F h_{i}=\sum_{n} q w_{i, n} \\
& \left(\text { Tcout }_{j}-t c_{j, 1}\right) \cdot F c_{j}=\sum_{m} q s_{m, j}
\end{aligned}
$$

Logical constraints:

$$
\begin{aligned}
& q_{i, j, k} \leq y_{i, j, k} \cdot\left[\min \left(F h_{i} \cdot\left(\text { Thin }_{i}-\text { Thout }_{i}\right), F c_{j} \cdot\left(\text { Tcout }_{j}-\text { Tcin }_{j}\right)\right)\right] \\
& q s_{m, j} \leq y s_{m, j} \cdot\left[\sum_{j} F c_{j} \cdot\left(\text { Tcout }_{j}-\text { Tcin }_{j}\right)\right] \\
& q w_{i, n} \leq y w_{i, n} \cdot\left[\sum_{i} F h_{i} \cdot\left(\text { Thin }_{i}-\text { Thout }_{i}\right)\right]
\end{aligned}
$$

Area constraints:

$$
\begin{aligned}
& \operatorname{area}_{i, j, k} \geq 1.0 \cdot y_{i, j, k} \\
& \operatorname{areas}_{m, j} \geq 1.0 \cdot y s_{m, j} \\
& \operatorname{areaw}_{i, n} \geq 1.0 \cdot y w_{i, n}
\end{aligned}
$$

Hot/cold end heat exchanger/heater/cooler temperature difference:

$$
\begin{aligned}
& d t h_{i, j, k}=t h_{i, k}-t c s_{i, j, k}+\left(\operatorname{Thin}_{i}-\operatorname{Tcin}_{j}\right) \cdot\left(1-y_{i, j, k}\right) \\
& d t c_{i, j, k}=t h s_{i, j, k}-t c_{j, k+1}+\left(\operatorname{Thin}_{i}-\operatorname{Tcin}_{j}\right) \cdot\left(1-y_{i, j, k}\right) \\
& d t s_{m, j}=\text { Tsout }_{m}-t c_{j, 1}+\left(\operatorname{Tsin}_{m}-\operatorname{Tcin}_{j}\right) \cdot\left(1-y s_{m, j}\right) \\
& d t w_{i, n}=\operatorname{th}_{i, \mathrm{NOK}+1}-\text { Twout }_{n}+\left(\operatorname{Thin}_{i}-\operatorname{Twin}_{n}\right) \cdot\left(1-y w_{i, n}\right)
\end{aligned}
$$$$
\text { Temperature difference bounds: }
$$

$$
m m t \geq \max \left\{\operatorname{Thin}_{i}\right\}-\max \left\{\operatorname{Tcin}_{j}\right\}
$$




$$
\begin{aligned}
& E M A T \leq d t h_{i, j, k} \leq m m t \\
& E M A T \leq d t c_{i, j, k} \leq m m t \\
& E M A T \leq d t s_{m, j} \leq\left(T \sin _{m}-T \operatorname{cin}_{j}\right) \\
& E M A T \leq d t w_{i, n} \leq\left(\operatorname{Thin}_{i}-\operatorname{Twin}_{n}\right) \\
& \text { Areas calculation: } \\
& q_{i, j, k}=C o_{i, j} \cdot \operatorname{area}_{i, j, k} \cdot\left(\frac{d t h_{i, j, k} \cdot d t c_{i, j, k} \cdot\left(d t h_{i, j, k}+d t c_{i, j, k}\right)}{2}\right)^{\frac{1}{3}} \\
& q s_{m, j}=\operatorname{Cos}_{m, j} \cdot \operatorname{areas}_{m, j} \cdot\left(\frac{d t s_{m, j} \cdot\left(T \sin _{m}-T \operatorname{cout}_{j}\right) \cdot\left(d t s_{m, j}+T \sin _{m}-T \operatorname{cout}_{j}\right)}{2}\right)^{1 / 3} \\
& q w_{i, n}=\operatorname{Cow}_{i, n} \cdot \operatorname{areaw}_{i, n} \cdot\left(\frac{d t w_{i, n} \cdot\left(\operatorname{Thout}_{i}-T w i n_{n}\right) \cdot\left(d t w_{i, n}+\text { Thout }_{i}-T w i_{n}\right)}{2}\right)^{1 / 3}
\end{aligned}
$$

Bounds for variables to be physically feasible:

$$
\begin{aligned}
& q_{i, j, k} \geq 0 \\
& q s_{m, j} \geq 0 \\
& q w_{i, n} \geq 0 \\
& r c_{i, j, k} \geq 0 \\
& r h_{i, j, k} \geq 0
\end{aligned}
$$

It is important to draw attention to constraints represented by Eqs. $26-32$. The first three equations constrain the search for HENs that do not possess heat transfer devices with areas extremely small, which are not feasible in practice for shell and tube heat exchangers. The last four of the mentioned constraints are written as equalities, which represent an improvement in the model of Jiang and Chang ${ }^{1}$, since the temperature differences in each end of heat transfer device were previously presented with relaxations (the reader is referred to Equations A.22 - A25 presented in Appendix A of the paper of Jiang and Chang ${ }^{1}$ ). Those relaxations lead to possible greater areas than those really required if outlet and inlet temperatures in each device are considered. Since the explicit variables (left hand side) in Eqs 29 - 32 are the 
temperature differences in hot or cold ends of heat exchangers, heaters and coolers, they must be strictly equal to the right hand sides of those equations. If a lower value than the right hand sides is allowed for any of these explicit variables, as done in the model of Jiang and Chang ${ }^{1}$, when the heat transfer device exists (binary variable is equal to one), logarithmic mean temperature difference may be lower than it really is for that specific heat transfer device and, so, areas may be greater than required. If the heat transfer device does not exist (binary variable is equal to zero), the value for the explicit variables in these equations does not matter, because the logical constraints lead the corresponding heat duty to be equal to zero and, consequently, corresponding area is zero (by Eqs. 38-40).

The multi-period HEN is obtained after finding the solution to each of the MINLP problems (i.e., each problem defined in each period). These networks must be integrated, which is achieved using an algorithmic procedure (Jiang and Chang ${ }^{1}$ ) in order to avoid doing this task by hand. This procedure consists of the following steps:

1. Organize, in decreasing order, all the heat exchanger areas for all periods;

2. Select the first area from the list and allocate the corresponding piece of equipment to the multi-period HEN. Consequently, the corresponding period, stage in the superstructure, and streams match are also assigned to this piece of equipment;

3. For the periods other than the one involved in the selection made in Step 2 , choose the greatest area in each period and allocate the corresponding process streams and stage in the superstructure to the piece of equipment that was allocated in the HEN in Step 2;

4. Remove from the list the areas used in Steps 2 and 3;

5. If the list is empty, end the procedure. Otherwise, return to Step 2.

The automatic procedure makes it possible to synthesize a HEN in which certain heat exchangers do not have fixed pairs of streams exchanging heat. Hence, it 
is possible that in one period the match is between one pair of streams, while in another period, a different pair of streams is matched in that piece of equipment. Since the procedure allows heat exchange between different process streams in different periods, a cleaning time must be allowed between different periods in order to avoid contamination inside the heat exchanger. Besides that, the different process streams may require different materials of construction and, therefore, heat exchangers must be constructed with a material able to deal with the different process streams. In addition, a set of bypasses must be designed to deal with variations in stream flow rates from one period to another, and to allocate the correct matching of streams in a certain period to each piece of equipment. This information is not included in the objective function and can increase the capital cost, due to the use of more valves and piping than if no change of stream pairs was allowed. However, the automatic procedure increases the search space for a HEN with minimum TAC, because it does not constrain the search to fixed matches in the different heat exchangers. Moreover, the procedure avoids excessive heat exchange areas in each period, since in each case the allocation of matches to each piece of equipment is based on decreasing the demanded areas.

\section{Case studies}

Three examples from the literature are used to test the performance of the developed model and the automatic procedure for synthesizing a multi-period HEN.

\subsection{Example 1}

This problem, proposed by Jiang and Chang ${ }^{1}$, considers two hot and two cold process streams, one hot utility and one cold utility, and operation of the final HEN in three equal time periods. Inlet and outlet temperatures and the stream flow rates can vary in the different periods. Table 1 presents the stream data. For the hot utility, the 
inlet and outlet temperatures are $680 \mathrm{~K}$, the convective heat transfer coefficient is 5 $\mathrm{kW} / \mathrm{m}^{2} \mathrm{~K}$, and its cost is $150,163 \$ /(\mathrm{kW}$ year). For the cold utility, the inlet and outlet temperatures are $300 \mathrm{~K}$ and $320 \mathrm{~K}$, respectively. The convective heat transfer coefficient is $1 \mathrm{~kW} / \mathrm{m}^{2} \mathrm{~K}$ and its cost is $53,064 \$ /(\mathrm{kW}$ year). The HEN capital cost (\$) is given by: Cost $=4333 \cdot$ Area $^{0.6}\left(\right.$ Area in $\left.m^{2}\right)$. The annual factor $(r)$ is $0.1 /$ year and EMAT is $10 \mathrm{~K}$.

For the solution of the problem, a HEN must be synthesized separately for each period. The MINLP problems were solved using GAMS 24.7.1 with DICOPT solver for the MINLP, with a processing time less than 1 second for all periods. The model had 108 equations and 101 variables, including 12 binary variables. Figure 1 presents the HENs for each period. Table 2 present the configurations of these networks, where $A_{s}$ is assigned area and $\operatorname{area}_{i, j, k} / A_{s}$ is the ratio of the calculated area to the assigned area. The results for each period of operation are summarized in Table S1 of the Supporting Information. The algorithmic procedure for automatic synthesis of the final HEN was applied, resulting in a capital cost of $33,201.80 \$ /$ year with total area of $497.8 \mathrm{~m}^{2}$ and 6 heat exchangers. It represents an area overdesign of $24 \%$ for Period 1, 6\% for Period 2 and $11 \%$ for Period 3 (pipeline network for this example in the three periods are presented in Figures S1-S3 of the Supporting Information). If to each heat exchanger only one fixed pair of streams could be assigned, i.e., if timesharing procedure was not used, the total area would be $514.3 \mathrm{~m}^{2}$ and 7 devices would be necessary. Table S2 of the Supporting Information presents the areas for each of the heat transfer devices. It may be obvious to the reader, but it is worth drawing attention to the fact that, during operation of each period, since greater heat transfer areas were assigned to some stream matches, stream bypasses should be properly implemented in order to meet the designed stage temperatures and the desired streams target temperatures. The calculation of the necessary bypasses is straightforward and is here illustrated for heat exchanger $(1,1,1)$. The solution for Period 1 determines that both streams should not be split and a heat exchange area of $66.0 \mathrm{~m}^{2}$ is necessary (Figure S4). However, due 
to an assigned area of $113.3 \mathrm{~m}^{2}, 32 \%$ of cold stream 1 should bypass the heat exchanger, so the heat exchanged and stage temperatures keep the same as those calculated for the period.

Table 3 compares the present results to those obtained by Jiang and Chang ${ }^{1}$. The TAC obtained by applying the developed model was $204,858.10$ \$year, representing an improvement on the earlier findings. The differences were in the capital costs, due to the multi-period HEN total area.

It is important here to stress that, the work of Jiang and Chang ${ }^{1}$ is supposed to not restrict the mixing to streams of same temperature, but this is not supported by their results, as it can be observed in Table S3, which shows their HEN for period 2 of Example 1. In this and in their other tables, there is an error. Lines 10 and 11 are presented with wrong nomenclature: $t_{j, k, p}^{C}$ must be $t_{j, k+1, p}^{C}$ and $t_{j, k+1, p}^{C}$ must be $t_{j, k, p}^{C}$. Table S3 indicates that heat exchanger $(1,1,1)$ is bypassed both by hot and cold streams. Figure S5 presents this heat exchanger designed by Jiang and Chang ${ }^{1}$, along with inlet and outlet temperatures. It is possible to observe that this device violates the Second Law of Thermodynamics, since the outlet temperature of hot stream (472.6 K) is lower than the inlet temperature of cold stream $(560.0 \mathrm{~K})$. If the analysis is made considering only the stage temperatures, the temperature difference is $10 \mathrm{~K}(570.0-$ $560.0 \mathrm{~K})$, as set by the authors, and this violation is not evident. It shows an inconsistency in the Jiang and Chang ${ }^{1}$ optimization model.

If heat exchanger $(2,2,2)$ of Table $S 3$ is also observed, it is possible to verify that both hot stream 2 and cold stream 2 have splitters in stage 2. Figure S6 presents this device and its inlet, outlet and stage temperatures. It is possible to conclude that heat exchanger $(2,2,2)$ has its area calculated based on the stage temperature and not on the hot stream outlet temperature. If the area calculation was performed with the true hot stream outlet temperature (which violates the minimum stipulated temperature difference), this device should have $118.3 \mathrm{~m}^{2}$, instead of $14.6 \mathrm{~m}^{2}$, as indicated in Table S3. This result presents the same inconsistency error as discussed above. 


\subsection{Example 2}

This problem was extracted from Floudas and Grossmann ${ }^{9}$. It was also solved by Isafiade and Fraser $^{27}$, Jiang and Chang $^{1}$ and Isafiade and co-workers ${ }^{30}$. There are two hot and two cold streams, one hot and one cold utility, and the HEN must operate in three equal periods. Inlet and outlet temperatures, as well as flow rates, can differ from one period to another. Table 4 shows the input data for the example. Global heat transfer coefficients and cost data are presented in Table 5.

An MINLP problem was solved for each period of operation using GAMS 24.7.1 with DICOPT, requiring less than 1 second in all cases. The model had 108 equations and 101 variables (including 12 binary variables). Figure 2 presents the HENs for each period. Table 6 shows the configurations of each HEN. Again, the algorithmic procedure to integrate the HENs obtained in the 3 periods was used. Table S4 presents the area for each piece of equipment. The annual factor $(r)$ used was 0.2 year, with 8600 hours in three periods of operation in one year and EMAT is $10{ }^{\circ} \mathrm{C}$. The final multi-period HEN had 6 heat transfer units with total area of $150.1 \mathrm{~m}^{2}$. No area overdesign is present for Period 1, but Periods 2 and 3 are overdesigned, respectively, in $59 \%$ and $35 \%$. If the timesharing procedure was not used, the total area would be $248.9 \mathrm{~m}^{2}$ and 8 devices would be necessary. Table 7 shows a comparison of the costs obtained by Floudas and Grossmann ${ }^{9}$, Isafiade and Fraser ${ }^{27}$, Jiang and Chang ${ }^{1}$, and Isafiade and co-workers ${ }^{30}$ with the present work, which resulted in a final multi-period HEN with TAC of 171,199 \$/year. It can be seen that in terms of the TAC, the proposed method provided better results than those obtained by Floudas and Grossmann ${ }^{9}$, Isafiade and Fraser $^{27}$ and Isafiade and co-workers ${ }^{30}$. The total annualized cost (TAC) of Jiang and Chang $^{1}$ is $170,084 \$$ year, however, besides presenting the same inconsistencies demonstrated for Example 1, the HEN proposed by Jiang and Chang ${ }^{1}$ has a heat exchanger with an area less than $1.0 \mathrm{~m}^{2}$, which is not 
feasible in practice. Utility costs in the present work were comparable to the values found by Floudas and Grossmann ${ }^{9}$ and Jiang and Chang ${ }^{1}$. The utility costs obtained by Isafiade and co-workers ${ }^{30}$ (calculated based on the HEN structure presented in Fig. 3 of their paper) were extremely large, while the corresponding capital cost was the lowest among all the previously reported values. This is not surprising, given that the HEN presented by Isafiade and co-workers ${ }^{30}$ did not exhibit any heat integration (in other words, there was no heat exchange between process streams). Only heaters and coolers were used, so capital costs were low, as expected, while utility costs were large. Another point concerning the work of Isafiade and co-workers ${ }^{30}$ is that the TAC values were incorrectly presented in $\$ / h$, instead of $\$ / y e a r$ (TAC stands for total annualized cost). This could mean that in their calculation, the capital cost was added (without transforming it to $\$ / \mathrm{h}$ ) to the utility costs on an hourly basis, which would explain the value of $125,371 \$ / \mathrm{h}$ presented in their work.

\subsection{Example 3}

This problem was adapted from Floudas and Grossmann ${ }^{10}$ and was used by Chen and Hung ${ }^{23}$, Isafiade and Fraser $^{27}$ and Jiang and Chang ${ }^{1}$. The problem has two hot and two cold streams, one hot and one cold utility, and the HEN must operate in four distinct periods. The inlet temperatures and flow rates of streams $\mathrm{H} 1$ and $\mathrm{C} 2$ can vary from one period to another. Table 8 presents the data for the streams. The hot utility inlet and outlet temperatures are $573 \mathrm{~K}$, and its cost is $0.0171428 \$ / \mathrm{kWh}$. The cold utility inlet and outlet temperatures are $303 \mathrm{~K}$ and $323 \mathrm{~K}$, respectively, and its cost is $0.0060576 \$ / \mathrm{kWh}$. The global heat transfer coefficients for all matches are 0.08 $\mathrm{kW} / \mathrm{m}^{2} \mathrm{~K}$, and the capital cost $(\$)$ is given by Cost $=4333 \cdot$ Area $^{0.6}\left(\right.$ Area in $\left.\mathrm{m}^{2}\right)$. The annual factor is $r=0.2 /$ year and EMAT is $10 \mathrm{~K}$.

By applying the systematic procedure, the HENs obtained for nominal conditions and for each period were as presented in Figure 3 and in Table 9. The MINLP model consisted of 108 equations and 101 variables (with 12 binary variables) 
and was solved for each period using GAMS 24.7.1 with DICOPT, requiring less than 1 second in all cases. The final multi-period HEN resulting from the automatic integration procedure is presented in Table S5. This work presents a TAC of 35,925 \$/year and total area of $110.2 \mathrm{~m}^{2}$. The area overdesign for nominal conditions and for Periods 1-3 are, respectively, $23 \%, 7 \%, 18 \%$ and $10 \%$. If to each heat exchanger only one fixed pair of streams could be assigned, the total area would be $178.8 \mathrm{~m}^{2}$ and 9 devices would be necessary. A comparison of the TAC obtained in the present work with previous results from the literature is presented in Table 10. As in Example 1, the TAC obtained using the proposed model was lower than the values reported previously in the literature. Furthermore, all HENs synthesized in this work have heat exchangers that are feasible in practice, since they present heat transfer areas greater than $1.0 \mathrm{~m}^{2}$. This is not true for the work of Isafiade and $\mathrm{Fraser}^{27}$ and Jiang and Chang ${ }^{1}$.

\section{Conclusions}

The present work proposes an optimization procedure to minimize the total annualized cost of a HEN operating in a finite number of time periods. The model has the formulation of an MINLP problem and uses the superstructure of Yee and Grossmann ${ }^{19}$, but isothermal mixing is not considered. Hence, energy balances for the mixers are necessary in the model. Besides that, in the model the temperature difference in both ends of each heat exchanger is calculated with true inlet and outlet temperatures in each heat transfer device. This step in the proposed model is different from the one of Jiang and Chang ${ }^{1}$, which presents an implementation error, using the stages temperatures instead of heat exchangers inlet and outlet streams temperatures. Another important difference between the models is that in the current paper constraints on calculated areas are considered, in order to avoid devices with tiny areas, which would be not feasible in practice. Furthermore, temperature difference in each end of heat transfer devices are calculated with equations, which differ from relaxations previously present in the literature. 
In the first step of the procedure, an optimal HEN is obtained separately for each period. In the following step, an algorithmic procedure, timesharing by Jiang and Chang $^{1}$, is used to integrate the different HENs and generate the final multi-period HEN. The multi-period network is generated considering the greatest areas and not fixing matches in each heat exchanger in different periods.

Three examples from the literature were used as case studies to test the performance of the developed model. The MINLP models were treated in GAMS 24.7.1, using the DICOPT solver. In Examples 1 and 3, in terms of the total annualized cost (TAC), the results obtained with the model developed here were better than the findings published previously in the literature. Total annualized cost of Example 2 is better than that found by Floudas and Grossmann ${ }^{9}$, Isafiade and Fraser ${ }^{27}$ and Isafiade and co-workers ${ }^{30}$, and, although slightly greater than the TAC obtained by Jiang and Chang ${ }^{1}$, it corresponds to a HEN in which all heat exchangers are feasible in practice, which is not true for all devices of the work of Jiang and Chang ${ }^{1}$.

\section{Nomenclature}

Indexes:

i hot stream

j cold stream

$m$ hot utility

n cold utility

$k \quad$ superstructure stage

Parameters:

a coefficient concerned to fixed cost in capital cost equation [\$]

b capital cost equation coefficient (area multiplier) $\left[\$ /\left(\mathrm{m}^{2 \mathrm{c}}\right)\right]$

c area exponent in capital cost equation [dimensionless] 
cost of hot utility $m[\$ /(\mathrm{kW}$ year $)$ or $\$ /(\mathrm{kWh})]$

cost of cold utility $n[\$ /(\mathrm{kW}$ year $)$ or $\$ /(\mathrm{kWh})]$ global heat transfer coefficient for heat exchanger $(i, j)\left[\mathrm{kW} /\left(\mathrm{m}^{2} \mathrm{~K}\right)\right]$ global heat transfer coefficient for heater $(m, j)\left[\mathrm{kW} /\left(\mathrm{m}^{2} \mathrm{~K}\right)\right]$ global heat transfer coefficient for heat exchanger $(i, n)\left[\mathrm{kW} /\left(\mathrm{m}^{2} \mathrm{~K}\right)\right]$ heat exchanger minimum approach temperature $\left[\mathrm{K}\right.$ or $\left.{ }^{\circ} \mathrm{C}\right]$ heat capacity of cold stream $j[\mathrm{~kW} / \mathrm{K}]$ heat capacity of hot stream $i[\mathrm{~kW} / \mathrm{K}]$ convective heat transfer coefficient of cold stream $j\left[\mathrm{~kW} /\left(\mathrm{m}^{2} \mathrm{~K}\right)\right]$ convective heat transfer coefficient of hot stream $i\left[\mathrm{~kW} /\left(\mathrm{m}^{2} \mathrm{~K}\right)\right]$ convective heat transfer coefficient of hot utility $m\left[\mathrm{~kW} /\left(\mathrm{m}^{2} \mathrm{~K}\right)\right]$ convective heat transfer coefficient of cold utility $n\left[\mathrm{~kW} /\left(\mathrm{m}^{2} \mathrm{~K}\right)\right]$ total number of stages in the superstructure [dimensionless] annual conversion factor [year ${ }^{-1}$ ] inlet temperature of cold stream $j\left[\mathrm{~K}\right.$ or $\left.{ }^{\circ} \mathrm{C}\right]$ outlet temperature of cold stream $j\left[\mathrm{~K}\right.$ or $\left.{ }^{\circ} \mathrm{C}\right]$ inlet temperature of hot stream $i\left[\mathrm{~K}\right.$ or $\left.{ }^{\circ} \mathrm{C}\right]$ outlet temperature of hot stream $i\left[\mathrm{~K}\right.$ or $\left.{ }^{\circ} \mathrm{C}\right]$ inlet temperature of hot utility $m\left[\mathrm{~K}\right.$ or $\left.{ }^{\circ} \mathrm{C}\right]$ outlet temperature of hot utility $m\left[\mathrm{~K}\right.$ or $\left.{ }^{\circ} \mathrm{C}\right]$ inlet temperature of cold utility $n\left[\mathrm{~K}\right.$ or $\left.{ }^{\circ} \mathrm{C}\right]$ outlet temperature of cold utility $n\left[\mathrm{~K}\right.$ or $\left.{ }^{\circ} \mathrm{C}\right]$

Binary variables:

$\begin{array}{ll}y_{i, j, k} & \text { indicates the existence of the heat exchanger }(i, j) \text { in stage } k \\ y s_{m, j} & \text { indicates the existence of the heater }(m, j) \\ y w_{i, n} & \text { indicates the existence of the cooler }(i, n)\end{array}$




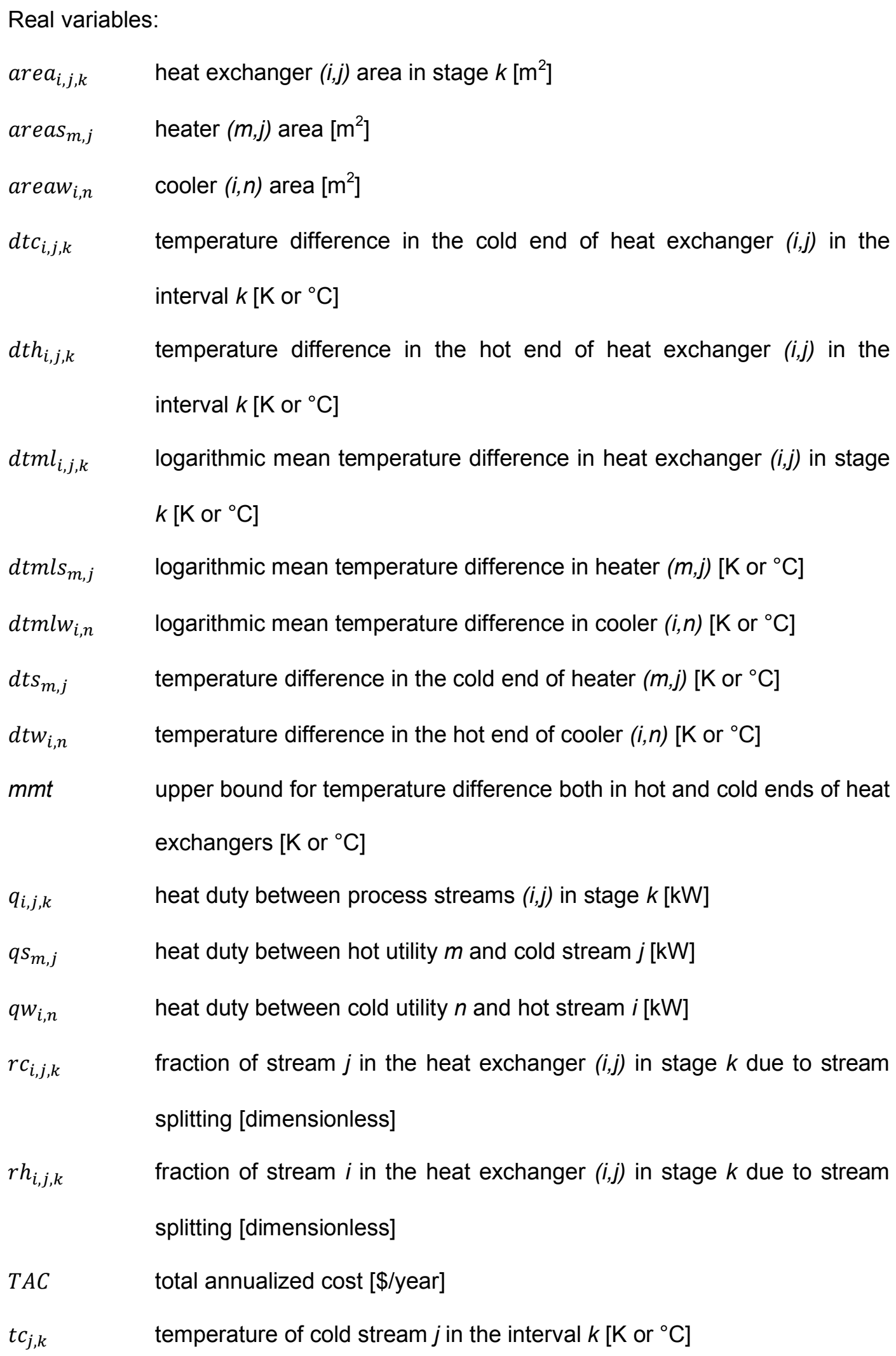


$t c s_{i, j, k} \quad$ outlet temperature of cold stream $j$ from heat exchanger $(i, j)$ in stage $k[\mathrm{~K}$ or $\left.{ }^{\circ} \mathrm{C}\right]$

$t h_{i, k} \quad$ temperature of hot stream $i$ in the interval $k\left[\mathrm{~K}\right.$ or $\left.{ }^{\circ} \mathrm{C}\right]$

ths $s_{i, j, k} \quad$ outlet temperature of hot stream $i$ from heat exchanger $(i, j)$ in stage $k[\mathrm{~K}$ or $\left.{ }^{\circ} \mathrm{C}\right]$

\section{Acknowledgements}

The authors acknowledge the support provided by CAPES (Coordination for the Improvement of Higher Education Personnel) - Brazilian Education Ministry.

\section{Supporting Information}

The Supporting Information is available free of charge on the ACS Publications website.

\section{References}

(1) Jiang, D.; Chang, C. T. A new approach to generate flexible multiperiod heat exchanger network designs with timesharing mechanisms. Ind. Eng. Chem. Res. 2013, $52,3794-3804$.

(2) Linnhoff, B.; Kotjabasakis, E. Downstream paths for operable process design. Chem. Eng. Prog. 1986, 82, 23-28.

(3) Kotjabasakis, E.; Linnhoff, B. Sensitivity tables for the design of flexible processes (1) - How much contingency in heat exchanger networks is cost-effective? Chem. Eng. Res. Des. 1986, 64, 197-211.

(4) Kotjabasakis, E. Design of flexible heat exchanger networks. Ph.D. Thesis, University of Manchester Institute of Science and Technology - UMIST, Manchester, U.K., February 1988. 
(5) Ravagnani, M. A. S. S.; Módenes, A. N. Heat exchanger networks with multiple periods of operation. Br. J. Chem. Eng. 1996, 13, 71-84.

(6) Floudas, C. A.; Grossmann, I. E. Synthesis of flexible heat exchanger networks for multiperiod operation. Comput. Chem. Eng. 1986, 10 (2), 153-168.

(7) Papoulias, S. A.; Grossmann, I. E. A structural optimization approach in process synthesis. Part II: Heat recovery networks. Comput. Chem. Eng. 1983, 7 (6), 707-721.

(8) Floudas, C. A.; Ciric, A. R.; Grossmann, I. E. Authomatic synthesis of optimum heat exchanger network configurations. AIChE J. 1986, 32 (2), 276-290.

(9) Floudas, C. A.; Grossmann, I. E. Automatic generation of multiperiod heat exchanger network configuration. Comput. Chem. Eng. 1987, 11 (2), 123-142.

(10) Floudas, C. A.; Grossmann, I. E. Synthesis of flexible heat exchanger networks with uncertain flowrates and temperatures. Comput. Chem. Eng. 1987, 11 (4), 319-336. (11) Cerdá, J.; Galli, M. R.; Camussi, N.; Isla, M. A. Synthesis of flexible heat exchanger networks - I. Convex networks. Comput. Chem. Eng. 1990, 14 (2), 197-211. (12) Cerdá, J.; Galli, M. R. Synthesis of flexible heat exchanger networks - II. Nonconvex networks with large temperature variations. Comput. Chem. Eng. 1990, 14 (2), 213-225.

(13) Galli, M. R.; Cerdá, J. Synthesis of flexible heat exchanger networks - III. Temperature and flowrate variations. Comput. Chem. Eng. 1991, 15 (1), 7-24.

(14) Papalexandri, K. P.; Pistikopoulos, E. N. A multiperiod MINLP model for improving the flexibility of heat exchanger networks. Comput. Chem. Eng. 1993, 17 (Suppl. 1), S111-S116.

(15) Papalexandri, K. P.; Pistikopoulos, E. N. A multiperiod MINLP model for the synthesis of flexible heat and mass exchange networks. Comput. Chem. Eng. 1994, 18 (11/12), 1125-1139.

(16) Aguilera, N.; Nasini, G. Flexibility test for heat exchanger networks with uncertain flowrates. Comput. Chem. Eng. 1995, 19 (9), 1007-1017. 
(17) Aguilera, N.; Marchetti, J. L. Optimizing and controlling the operation of heatexchanger networks. AIChE J. 1998, 44 (5), 1090-1104.

(18) Aaltola, J. Simultaneous synthesis of flexible heat exchanger network. Appl. Thermal Eng. 2002, 22, 907-918.

(19) Yee, T. F.; Grossmann, I. E. Simultaneous optimization models for heat integration - II. Heat exchanger network synthesis. Comput. Chem. Eng. 1990, 14 (10). 11651184.

(20) Yee, T. F.; Grossmann, I. E.; Kravanja, Z. Simultaneous optimization models for heat integration - III. Process and heat exchanger network optimization. Comput. Chem. Eng. 1990, 14 (11), 1185-1200.

(21) Konukman, A. E. S.; Çamurdan, M. C.; Akman, U. Simultaneous flexibility targeting and synthesis of minimum-utility heat-exchanger networks with superstructure-based MILP formulation. Chem. Eng. Process. 2002, 41, 501-518.

(22) Chen, C. L.; Kuo, C. H.; Hung, P. S. A novel strategy for synthesis of flexible heatexchange networks. J. Chin. Inst. Chem. Eng. 2005, 36 (5), 421-432.

(23) Chen, C. L.; Hung, P. S. Simultaneous synthesis of flexible heat-exchange networks with uncertain source-stream temperatures and flow rates. Ind. Eng. Chem. Res. 2004, 43 (18), 5916-5928.

(24) Verheyen, W.; Zhang, N. Design of flexible heat exchanger network for multiperiod operation. Chem. Eng. Sci. 2006, 61, 7730-7753.

(25) Chen, C. L.; Hung, P. S. Synthesis of flexible heat exchange networks and mass exchange networks. Comput. Chem. Eng. 2007, 31, 1619-1632.

(26) Isafiade, A. J.; Fraser, D. M. Interval-based MINLP superstructure synthesis of heat exchanger networks. Chem. Eng. Res. Des. 2008, 86, 245-257.

(27) Isafiade, A. J.; Fraser, D. M. Interval based MINLP superstructure synthesis of heat exchanger networks for multi-period operations. Chem. Eng. Res. Des. 2010, 88, $1329-1341$. 
(28) El-Temtamy, S. A.; Gabr, E. M. Design of optimum flexible heat exchanger networks for multiperiod process. Egypt. J. Petrol. 2012, 21, 109-117.

(29) Escobar, M.; Trierweiler, J. O.; Grossmann, I. E. Simultaneous synthesis of heat exchanger networks with operability considerations: Flexibility and controllability. Comput. Chem. Eng. 2013, 55, 158-180.

(30) Isafiade, A. J.; Bogataj, M.; Fraser, D.; Kravanja, Z. Optimal synthesis of heat exchanger networks for multi-period operations involving single and multiple utilities. Chem. Eng. Sci. 2015, 127, 175-188.

(31) Ma, X.; Yao, P.; Luo, X.; Roetzel, W. Synthesis of flexible multi-stream heat exchanger networks based on stream pseudo-temperature with genetic/simulated annealing algorithms. J. Chin. Inst. Chem. Eng. 2007, 38, 321-331.

(32) Ma, X.; Yao, P.; Luo, X.; Roetzel, W. Synthesis of multi-stream heat exchanger network for multi-period operation with genetic/simulated annealing algorithms. Appl. Thermal Eng. 2008, 28, 809-823.

(33) Xiao, F.; Du, J.; Liu, L.; Luan, G.; Yao, P. Simultaneous optimization of synthesis and scheduling of cleaning in flexible heat exchanger networks. Chin. J. Chem. Eng. 2010, $18(3), 402-411$.

(34) Ahmad, M. I.; Zhang, N.; Jobson, M.; Chen, L. Multi-period design of heat exchanger networks. Chem. Eng. Res. Des. 2012, 90, 1883-1895.

(35) Yi, D.; Han, Z.; Wang, K.; Yao, P. Strategy for synthesis of flexible heat exchanger networks embedded with system reliability analysis. Chin. J. Chem. Eng. 2013, 21 (7), 742-753.

(36) Nemet, A.; Klemes, J. J.; Kravanja, Z. Optimising entire lifetime economy of heat exchanger networks. Energy. 2013, 57, 222-235.

(37) Li, J.; Du, J.; Zhao, Z.; Yao, P. Structure and area optimization of flexible heat exchanger networks. Ind. Eng. Chem. Res. 2014, 53, 11779-11793.

(38) Chen, J. J. J. Letters to the editors: comments on improvements on a replacement for the logarithmic mean. Chem. Eng. Sci. 1987, 42 (10), 2488-2489. 


\section{Apendix - Variables initialization procedure}

Due to the nonlinearitires present in the model, an initialization procedure for the variables is presented.

For the area upper limits, known values from the literature may be used as initial estimate, if they exist. For example, if the problem has a known solution, the greatest heat exchanger area in the HEN can be used as the upper bound.

The variables rh and $\mathrm{rc}$ are the by-pass fractions and it can vary from 0 to 1. These values may be varied from 0 to 1 , with a step of 0.1 .

For the temperature limits, the initialization procedure suggested by Yee and Grossmann ${ }^{19}$ may be used.

The variables suffix are:. up $=$ upper bound; $. l o=$ lower bound; $. I=$ initial estimate. The index $i, j$ and $k$ represents hot streams, cold streams and the superstructure stages.

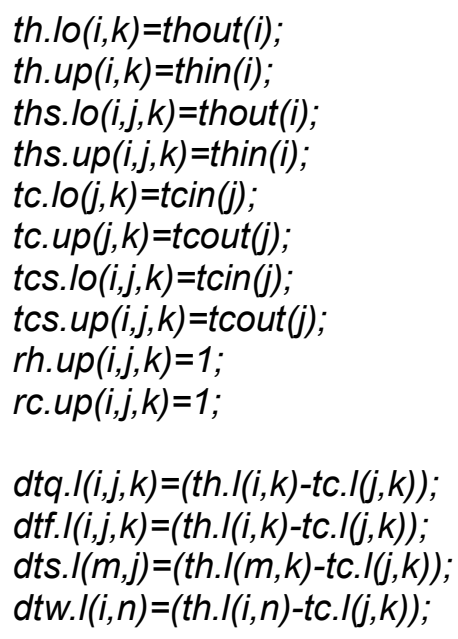

area.up $(i, j, k)=$ largest heat exchanger area from all the HEN published in the literature for the problem studied, if it exists; otherwise, a large value, such as $10,000 \mathrm{~m}^{2}$, could be used;

areaw.up $(i, n)=$ largest heat exchanger area from all the HEN published in the literature for the problem studied, if it exists; otherwise, a large value, such as $10,000 \mathrm{~m}^{2}$, could be used; 
areas.up $(m, j)=$ largest heat exchanger area from all the HEN published in the literature for the problem studied, if it exists; otherwise, a large value, such as 10,000 $\mathrm{m}^{2}$, could be used;

parameter incth(i), inctc(j);

incth(i)=(thin(i)-thout(i))/(card(k)-1);

$\operatorname{inctc}(j)=(\operatorname{tcout}(j)-\operatorname{tcin}(j)) /(\operatorname{card}(k)-1)$;

th. $I(i, k)=\operatorname{thin}(i)-i n c t h(i) *(\operatorname{ord}(k)-1)$;

tc. $I(j, k)=$ tcout $(j)$-inctc $(j)^{*}($ ord $(k)-1)$;

ths. $I(i, j, k)=\operatorname{thin}(i)-\operatorname{incth}(i)^{*}(\operatorname{ord}(k))$;

tcs. $I(i, j, k)=$ tcout $(j)-\operatorname{inctc}(j)^{*}($ ord $(k)-2)$; 


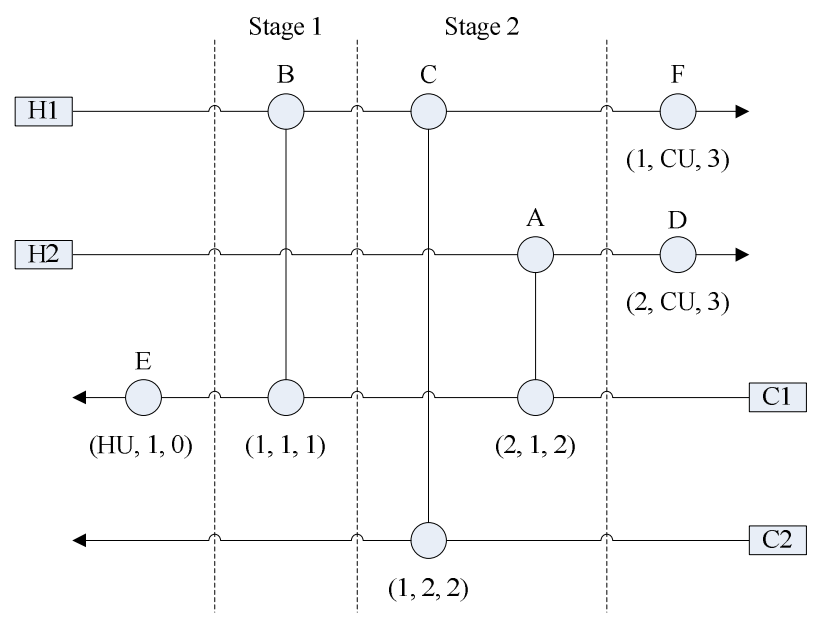

(a)

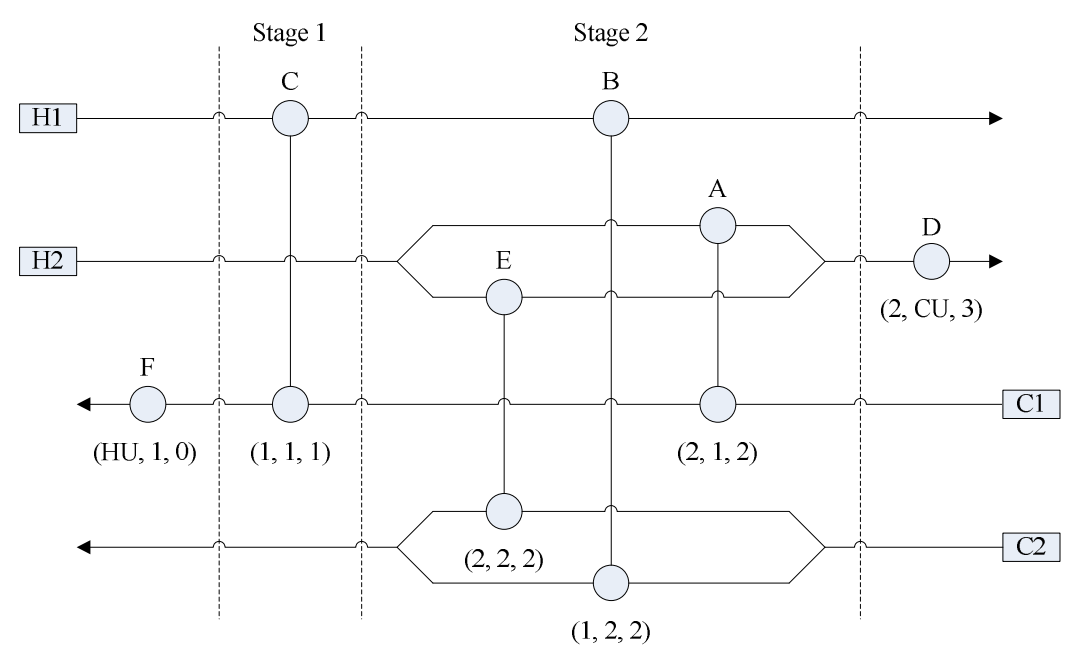

(b)

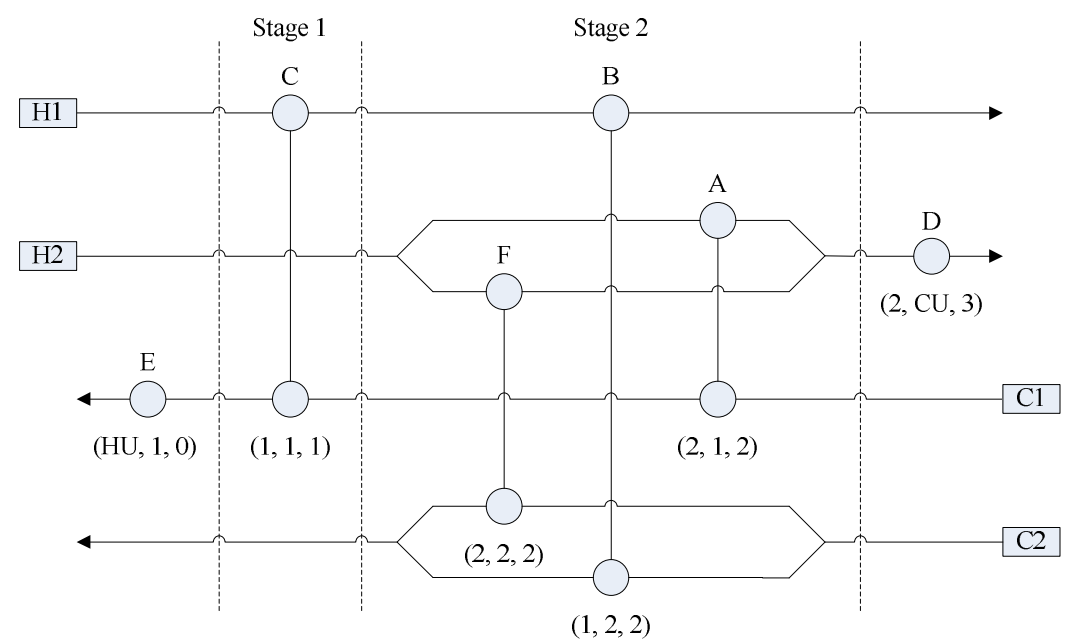

(c)

Figure 1: HEN in Example 1. (a) Period 1. (b) Period 2. (c) Period 3 


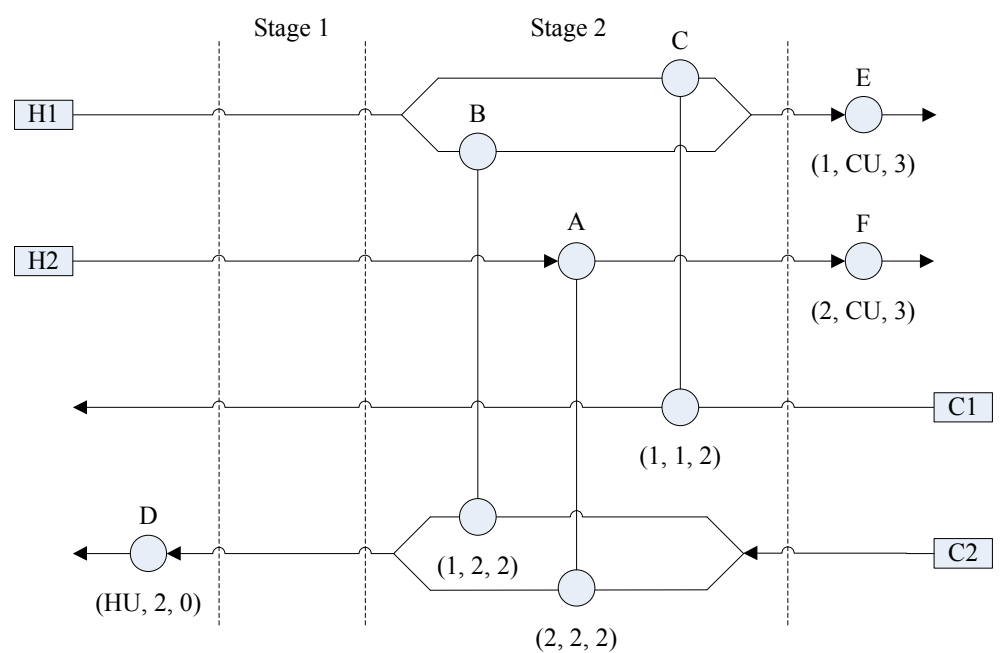

(a)

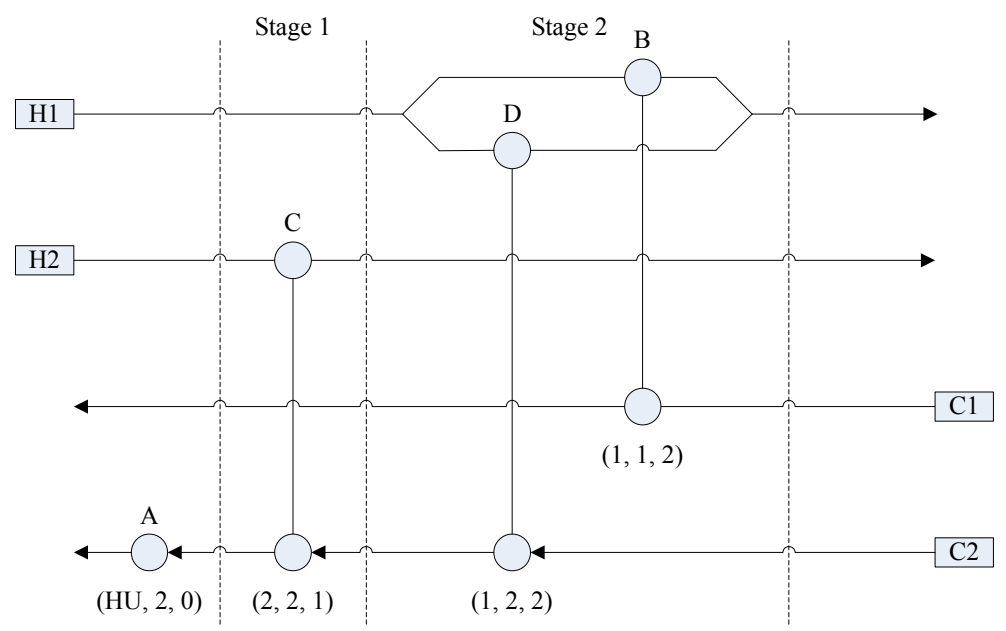

(b)

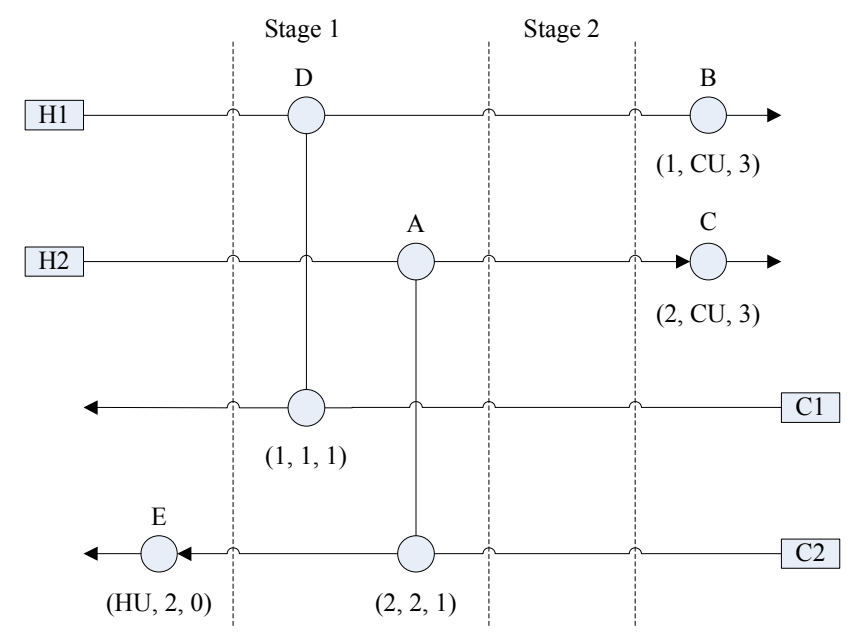

(c)

Figure 2: HEN in Example 2. (a) Period 1. (b) Period 2. (c) Period 3 


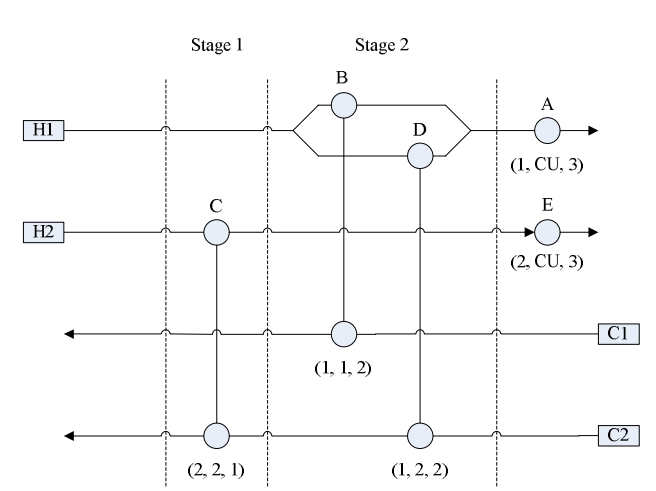

(a)

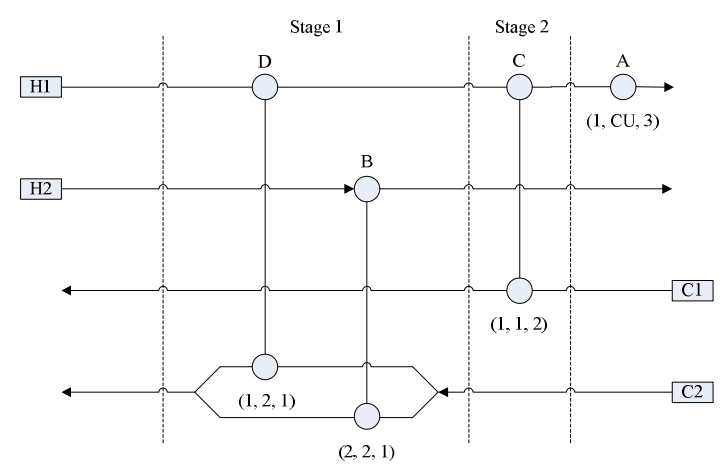

(b)

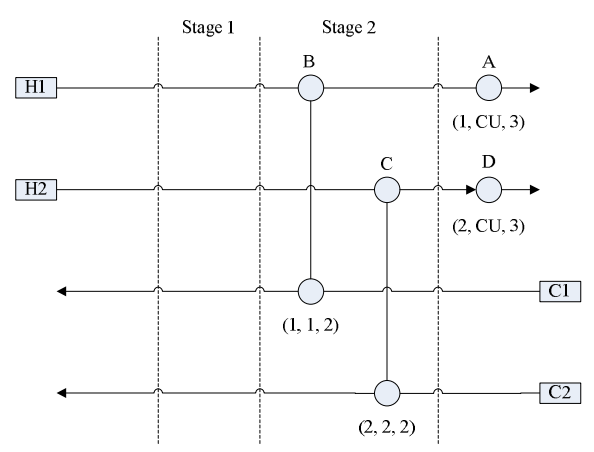

(c)

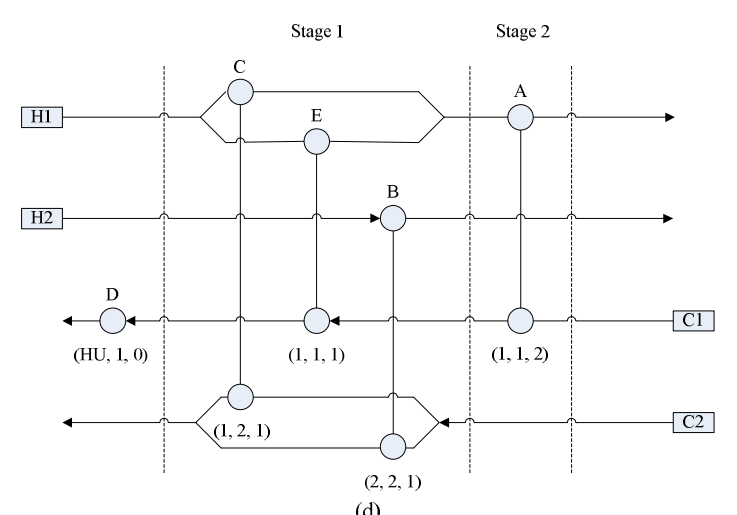

Figure 3: HEN in Example 3. (a) Nominal conditions. (b) Period 1. (c) Period 2. (d)

Period 3 
Table 1 - Streams data for Example 1

\begin{tabular}{ccccc}
\hline Stream & Tin $(K)$ & Tout $(K)$ & $F(k W / K)$ & $h\left(k W /\left(m^{2} K\right)\right)$ \\
\hline Period 1 & & & 10 & 1 \\
H1 & 650 & 370 & 20 & 1 \\
C1 & 590 & 370 & 15 & 1 \\
C2 & 410 & 640 & 13 & 1 \\
Period 2 & 350 & 500 & 10.2 & 1.03 \\
H1 & 630 & 380 & 20.5 & 1.04 \\
H2 & 570 & 340 & 15 & 1.02 \\
C1 & 390 & 630 & 13.5 & 1.05 \\
C2 & 340 & 520 & & \\
Period 3 & & & 10 & 1.01 \\
H1 & 645 & 350 & 20.3 & 1.04 \\
H2 & 600 & 350 & 14.3 & 1.05 \\
C1 & 420 & 660 & 13 & 1.03 \\
C2 & 320 & 540 & & \\
\hline
\end{tabular}

40

41

42

43

44

45

46

47

48

49

50

51

52

53

54

55

56

57

58

59

60 
Table 2 - HEN data for periods 1, 2 and 3 of Example 1

\begin{tabular}{|c|c|c|c|c|c|c|c|c|}
\hline Match & $(i, j, k)$ & $(1,1,1)$ & $(1,2,2)$ & $(2,1,2)$ & $(2,2,2)$ & $(1, C U, 3)$ & $(2, C U, 3)$ & $(H U, 1,0)$ \\
\hline \multicolumn{9}{|l|}{ Period 1} \\
\hline$A_{s}$ & $m^{2}$ & 113.3 & 66.8 & 236.2 & - & 8.1 & 50.8 & 22.6 \\
\hline $\operatorname{area}_{i, j, k}$ & $m^{2}$ & 66.0 & 60.1 & 200.7 & - & 6.9 & 36.3 & 7.3 \\
\hline $\operatorname{area}_{i, j, k} / A_{s}$ & $\%$ & 58.2 & 90.0 & 85.0 & - & 85.2 & 71.5 & 32.3 \\
\hline$q_{i, j, k}$ & $k W$ & 600.0 & 1950.0 & 2550.0 & - & 250.0 & 1850.0 & 300.0 \\
\hline$r h_{i, j, k}$ & & 1.0 & 1.0 & 1.0 & - & 1.0 & 1.0 & \\
\hline$r c_{i, j, k}$ & & 1.0 & 1.0 & 1.0 & - & & & 1.0 \\
\hline$t h_{i, k}$ & K & 650.0 & 590.0 & 590.0 & - & 395.0 & 462.5 & 680.0 \\
\hline$t h_{i, k+1}$ & K & 590.0 & 395.0 & 462.5 & - & 370.0 & 370.0 & 680.0 \\
\hline$t h s_{i, j, k}$ & K & 590.0 & 395.0 & 462.5 & - & 370.0 & 370.0 & 680.0 \\
\hline$t c_{j, k+1}$ & K & 580.0 & 350.0 & 410.0 & - & 300.0 & 300.0 & 620.0 \\
\hline$t c_{j, k}$ & K & 620.0 & 500.0 & 580.0 & - & 320.0 & 320.0 & 640.0 \\
\hline$t c s_{i, j, k}$ & K & 620.0 & 500.0 & 580.0 & - & 320.0 & 320.0 & 640.0 \\
\hline \multicolumn{9}{|l|}{ Period 2} \\
\hline$A_{s}$ & $m^{2}$ & 66.8 & 113.3 & 236.2 & 22.6 & - & 50.8 & 8.1 \\
\hline $\operatorname{area}_{i, j, k}$ & $m^{2}$ & 66.8 & 83.2 & 236.2 & 22.6 & - & 49.7 & 8.1 \\
\hline $\operatorname{area}_{i, j, k} / A_{s}$ & $\%$ & 100.0 & 73.4 & 100.0 & 100.0 & - & 97.8 & 100.0 \\
\hline$q_{i, j, k}$ & $k W$ & 612.0 & 1938.0 & 2550.0 & 492.0 & - & 1673.0 & 438.0 \\
\hline$r h_{i, j, k}$ & & 1.0 & 1.0 & 0.877 & 0.123 & - & 1.0 & \\
\hline$r c_{i, j, k}$ & & 1.0 & 0.798 & 1.0 & 0.202 & - & & 1.0 \\
\hline$t h_{i, k}$ & K & 630.0 & 570.0 & 570.0 & 570.0 & - & 421.6 & 680.0 \\
\hline$t h_{i, k+1}$ & K & 570.0 & 380.0 & 421.6 & 421.6 & - & 340.0 & 680.0 \\
\hline$t h s_{i, j, k}$ & K & 570.0 & 380.0 & 428.2 & 374.3 & - & 340.0 & 680.0 \\
\hline$t c_{j, k+1}$ & K & 560.0 & 340.0 & 390.0 & 340.0 & - & 300.0 & 600.8 \\
\hline$t c_{j, k}$ & $K$ & 600.8 & 520.0 & 560.0 & 520.0 & - & 320.0 & 630.0 \\
\hline$t c s_{i, j, k}$ & K & 600.8 & 520.0 & 560.0 & 520.0 & - & 320.0 & 630.0 \\
\hline \multicolumn{9}{|l|}{ Period 3} \\
\hline$A_{s}$ & $m^{2}$ & 66.8 & 113.3 & 236.2 & 8.1 & - & 50.8 & 22.6 \\
\hline $\operatorname{area}_{i, j, k}$ & $m^{2}$ & 55.3 & 113.3 & 200.6 & 8.0 & - & 50.8 & 17.7 \\
\hline $\operatorname{area}_{i, j, k} / A_{s}$ & $\%$ & 82.8 & 100.0 & 84.9 & 98.8 & - & 100.0 & 78.3 \\
\hline$q_{i, j, k}$ & $k W$ & 450.0 & 2500.0 & 2431.0 & 360.0 & - & 2284.0 & 551.0 \\
\hline$r h_{i, j, k}$ & & 1.0 & 1.0 & 0.888 & 0.112 & - & 1.0 & \\
\hline$r c_{i, j, k}$ & & 1.0 & 0.874 & 1.0 & 0.126 & - & & 1.0 \\
\hline$t h_{i, k}$ & K & 645.0 & 600.0 & 600.0 & 600.0 & - & 462.5 & 680.0 \\
\hline$t h_{i, k+1}$ & K & 600.0 & 350.0 & 462.5 & 462.5 & - & 350.0 & 680.0 \\
\hline$t h s_{i, j, k}$ & K & 600.0 & 350.0 & 465.2 & 441.0 & - & 350.0 & 680.0 \\
\hline$t c_{j, k+1}$ & $K$ & 590.0 & 320.0 & 420.0 & 320.0 & - & 300.0 & 621.5 \\
\hline$t c_{j, k}$ & K & 621.5 & 540.0 & 590.0 & 540.0 & - & 320.0 & 660.0 \\
\hline$t c s_{i, j, k}$ & $K$ & 621.5 & 540.0 & 590.0 & 540.0 & - & 320.0 & 660.0 \\
\hline
\end{tabular}


Table 3 - Total area and costs comparison for Example 1

\begin{tabular}{lccccc} 
& $\begin{array}{c}\text { Number of heat } \\
\text { transfer units }\end{array}$ & $\begin{array}{c}\text { Total area } \\
\left(m^{2}\right)\end{array}$ & CC $(\$ / y r)$ & OC $(\$ / y r)$ & TAC $(\$ / y r)$ \\
\hline Jiang and Chang ${ }^{1}$ & 6 & 521.1 & $33,627.00$ & $171,656.30$ & $205,283.20$ \\
This study & 6 & 497.8 & $33,201.80$ & $171,656.30$ & $204,858.10$ \\
\hline
\end{tabular}


Table 4: Streams data for Example 2

\begin{tabular}{|c|c|c|c|}
\hline Stream & $\operatorname{Tin}\left({ }^{\circ} \mathrm{C}\right)$ & Tout $\left({ }^{\circ} \mathrm{C}\right)$ & $\mathrm{F}\left(\mathrm{kW} /{ }^{\circ} \mathrm{C}\right)$ \\
\hline \multicolumn{4}{|l|}{ Period 1} \\
\hline $\mathrm{H} 1$ & 249 & 100 & 10.55 \\
\hline $\mathrm{H} 2$ & 259 & 128 & 12.66 \\
\hline C1 & 96 & 170 & 9.144 \\
\hline $\mathrm{C} 2$ & 106 & 270 & 15 \\
\hline \multicolumn{4}{|l|}{ Period 2} \\
\hline $\mathrm{H} 1$ & 229 & 120 & 7.032 \\
\hline $\mathrm{H} 2$ & 239 & 148 & 8.44 \\
\hline C1 & 96 & 170 & 9.144 \\
\hline $\mathrm{C} 2$ & 106 & 270 & 15 \\
\hline \multicolumn{4}{|l|}{ Period 3} \\
\hline $\mathrm{H} 1$ & 249 & 100 & 10.55 \\
\hline $\mathrm{H} 2$ & 259 & 128 & 12.66 \\
\hline C1 & 116 & 150 & 6.096 \\
\hline $\mathrm{C} 2$ & 126 & 250 & 10 \\
\hline
\end{tabular}


Table 5: Heat transfer coefficients and cost data for Example 2

\begin{tabular}{ccc}
\hline Unit & Match & $\mathrm{Co}_{u}\left(\mathrm{~kW} /\left(\mathrm{m}^{2} .{ }^{\circ} \mathrm{C}\right)\right)$ \\
\hline 1 & $\mathrm{HU}-\mathrm{C} 2$ & 0.8 \\
2 & $\mathrm{H} 2-\mathrm{C} 2$ & 1 \\
3 & $\mathrm{H} 1-\mathrm{C} 1$ & 1 \\
4 & $\mathrm{H} 1-\mathrm{C} 2$ & 1 \\
5 & $\mathrm{H} 2-\mathrm{C} 2$ & 1 \\
6 & $\mathrm{H} 1-\mathrm{CU}$ & 0.4 \\
7 & $\mathrm{H} 2-\mathrm{CU}$ & 0.3 \\
Cost $=4333 \cdot{ }^{\text {Area }}{ }^{0.6}$, Area $[=] \mathrm{m}^{2}$. \\
$\mathrm{HU} \operatorname{cost}\left(300-300{ }^{\circ} \mathrm{C}\right)=171.428 \times 10^{-4} \$ / \mathrm{kWh}$. \\
$\mathrm{CU} \operatorname{cost}\left(30-50{ }^{\circ} \mathrm{C}\right)=60.576 \times 10^{-4} \$ / \mathrm{kWh}$.
\end{tabular}

29

30

31

32

33

34

35

36

37

38

39

40

41

42

43

44

45

46

47

48

49

50

51

52

53

54

55

56

57

58

59

60 
Table 6: HEN data for periods 1, 2 and 3 of Example 2

\begin{tabular}{|c|c|c|c|c|c|c|c|c|c|}
\hline \multirow{2}{*}{$\begin{array}{c}\text { Match } \\
\text { Period } 1\end{array}$} & \multicolumn{2}{|c|}{$(i, j, k)(1,1,1)$} & \multirow[t]{2}{*}{$(1,1,2)$} & \multirow[t]{2}{*}{$(1,2,2)$} & \multirow[t]{2}{*}{$(2,2,1)$} & \multirow[t]{2}{*}{$(2,2,2)$} & \multicolumn{2}{|c|}{$(1, C U, 3)(2, C U, 3)$} & \multirow[t]{2}{*}{$(H U, 2,0)$} \\
\hline & & & & & & & & & \\
\hline$A_{s}$ & $m^{2}$ & - & 17.0 & 36.1 & - & 70.0 & 8.9 & 7.0 & 11.1 \\
\hline area $_{i, j, k}$ & $m^{2}$ & - & 17.0 & 36.1 & - & 70.0 & 8.9 & 7.0 & 11.1 \\
\hline $\operatorname{area}_{i, j, k} / A_{s}$ & $\%$ & - & 100.0 & 100.0 & - & 100.0 & 100.0 & 100.0 & 100.0 \\
\hline$q_{i, j, k}$ & $k W$ & - & 676.6 & 638.7 & - & 1458.2 & 256.6 & 200.2 & 363.0 \\
\hline$r h_{i, j, k}$ & & - & 0.471 & 0.529 & - & 1.0 & 1.0 & 1.0 & \\
\hline$r c_{i, j, k}$ & & - & 1.0 & 0.320 & - & 0.680 & & & 1.0 \\
\hline$t h_{i, k}$ & $K$ & - & 249.0 & 249.0 & - & 259.0 & 124.3 & 143.8 & 300.0 \\
\hline$t h_{i, k+1}$ & $K$ & - & 124.3 & 124.3 & - & 143.8 & 100.0 & 128.0 & 300.0 \\
\hline$t h s_{i, j, k}$ & $K$ & - & 112.7 & 134.6 & - & 143.8 & 100.0 & 128.0 & 300.0 \\
\hline$t c_{j, k+1}$ & K & - & 96.0 & 106.0 & - & 106.0 & 30.0 & 30.0 & 245.8 \\
\hline$t c_{j, k}$ & K & - & 170.0 & 245.8 & - & 245.8 & 50.0 & 50.0 & 270.0 \\
\hline$t c s_{i, j, k}$ & K & - & 170.0 & 239.0 & - & 249.0 & 50.0 & 50.0 & 270.0 \\
\hline \multicolumn{10}{|l|}{ Period 2} \\
\hline$A_{s}$ & $m^{2}$ & - & 36.1 & 11.1 & 17.0 & - & - & - & 70.0 \\
\hline area $_{i, j, k}$ & $m^{2}$ & - & 17.4 & 1.9 & 14.4 & - & - & - & 28.6 \\
\hline $\operatorname{area}_{i, j, k} / A_{s}$ & $\%$ & - & 48.2 & 17.1 & 84.7 & - & - & - & 40.8 \\
\hline$q_{i, j, k}$ & $k W$ & - & 676.6 & 89.8 & 768.0 & - & - & - & 1602.1 \\
\hline$r h_{i, j, k}$ & & - & 0.883 & 0.117 & 1.0 & - & - & - & \\
\hline$r c_{i, j, k}$ & & - & 1.0 & 1.0 & 1.0 & - & - & - & 1.0 \\
\hline$t h_{i, k}$ & $K$ & - & 229.0 & 229.0 & 239.0 & - & - & - & 300.0 \\
\hline$t h_{i, k+1}$ & K & - & 120.0 & 120.0 & 148.0 & - & - & - & 300.0 \\
\hline$t h s_{i, j, k}$ & $K$ & - & 120.0 & 120.0 & 148.0 & - & - & - & 300.0 \\
\hline$t c_{j, k+1}$ & K & - & 96.0 & 106.0 & 112.0 & - & - & - & 163.2 \\
\hline$t c_{j, k}$ & K & - & 170.0 & 112.0 & 163.2 & - & - & - & 270.0 \\
\hline$t c s_{i, j, k}$ & K & - & 170.0 & 112.0 & 163.2 & - & - & - & 270.0 \\
\hline \multicolumn{10}{|l|}{ Period 3} \\
\hline$A_{s}$ & $m^{2}$ & 11.1 & - & - & 70.0 & - & 36.1 & 17.0 & 8.9 \\
\hline area $_{i, j, k}$ & $m^{2}$ & 1.9 & - & - & 51.0 & - & 29.4 & 14.5 & 1.0 \\
\hline $\operatorname{area}_{i, j, k} / A_{s}$ & $\%$ & 17.1 & - & - & 72.8 & - & 81.4 & 85.3 & 11.2 \\
\hline$q_{i, j, k}$ & $k W$ & 207.3 & - & - & 1198.3 & - & 1364.7 & 460.1 & 41.6 \\
\hline$r h_{i, j, k}$ & & 1.0 & - & - & 1.0 & - & 1.0 & 1.0 & \\
\hline$r c_{i, j, k}$ & & 1.0 & - & - & 1.0 & - & & & 1.0 \\
\hline$t h_{i, k}$ & $K$ & 249.0 & - & - & 259.0 & - & 229.3 & 164.3 & 300.0 \\
\hline$t h_{i, k+1}$ & K & 229.3 & - & - & 164.3 & - & 100.0 & 128.0 & 300.0 \\
\hline$t h s_{i, j, k}$ & $K$ & 229.3 & - & - & 164.3 & - & 100.0 & 128.0 & 300.0 \\
\hline$t c_{j, k+1}$ & $K$ & 116.0 & - & - & 126.0 & - & 30.0 & 30.0 & 245.8 \\
\hline$t c_{j, k}$ & K & 150.0 & - & - & 245.8 & - & 50.0 & 50.0 & 250.0 \\
\hline$t c s_{i, j, k}$ & $K$ & 150.0 & - & - & 245.8 & - & 50.0 & 50.0 & 250.0 \\
\hline
\end{tabular}


Table 7: Costs comparison for Example 2

\begin{tabular}{|c|c|c|c|}
\hline & $\begin{array}{c}\text { OC } \\
(\$ / y r)\end{array}$ & $\begin{array}{c}\text { CC } \\
(\$ / y r)\end{array}$ & $\begin{array}{l}\text { TAC } \\
(\$ / y r)\end{array}$ \\
\hline Floudas and Grossmann $^{9}$ & 134,492 & 53,876 & 188,368 \\
\hline Isafiade and Fraser ${ }^{27}$ & 314,731 & 26,926 & 341,657 \\
\hline Jiang and Chang ${ }^{1}$ & 134,496 & 35,588 & 170,084 \\
\hline Isafiade and co-workers ${ }^{30}$ & 518,236 & 24,263 & 542,499 \\
\hline This study & 138,239 & 32,960 & 171,199 \\
\hline
\end{tabular}

17 
1

2

3

4

5

6

7

8

9

10

11

12

13

14

15

16

17

18

19

20

21

22

23

24

25

26

27

28

29

30

31

32

33

34

35

36

37

38

39

40

41

42

43

44

45

46

47

48

49

50

51

52

53

54

55

56

57

58

59

60

Table 8: Streams data for Example 3

\begin{tabular}{cccc}
\hline Stream & Tin $(K)$ & Tout $(K)$ & $F(k W / K)$ \\
\hline Nominal conditions & & & \\
H1 & 583 & 323 & 1.4 \\
H2 & 723 & 553 & 2.0 \\
C1 & 313 & 393 & 3.0 \\
C2 & 388 & 553 & 2.0
\end{tabular}

Period 1

$\begin{array}{llll}\mathrm{H} 1 & 593 & 323 & 1.8\end{array}$

$\begin{array}{llll}\mathrm{H} 2 & 723 & 553 & 2.0\end{array}$

$\begin{array}{llll}\mathrm{C} 1 & 313 & 393 & 3.0\end{array}$

$\begin{array}{llll}\mathrm{C} 2 & 383 & 553 & 2.4\end{array}$

Period 2

$\begin{array}{llll}\mathrm{H} 1 & 593 & 323 & 1.8\end{array}$

$\begin{array}{llll}\mathrm{H} 2 & 723 & 553 & 2.0\end{array}$

$\begin{array}{llll}\mathrm{C} 1 & 313 & 393 & 3.0\end{array}$

$\begin{array}{llll}\mathrm{C} 2 & 393 & 553 & 1.6\end{array}$

Period 3

$\begin{array}{llll}\mathrm{H} 1 & 573 & 323 & 1.0\end{array}$

$\begin{array}{llll}\mathrm{H} 2 & 723 & 553 & 2.0\end{array}$

$\begin{array}{llll}\mathrm{C} 1 & 313 & 393 & 3.0\end{array}$

$\begin{array}{llll}\mathrm{C} 2 & 383 & 553 & 2.4\end{array}$


Table 9 - HEN data for nominal conditions, periods 1, 2 and 3 of Example 3

\begin{tabular}{|c|c|c|c|c|c|c|c|c|c|c|}
\hline \multirow{2}{*}{\multicolumn{11}{|c|}{ Nominal conditions }} \\
\hline & & & & & & & & & & \\
\hline$A_{S}$ & $m^{2}$ & - & 25.0 & - & 9.4 & 22.4 & - & 51.4 & 2.0 & - \\
\hline $\operatorname{area}_{i, j, k}$ & $m^{2}$ & - & 24.1 & - & 6.7 & 22.0 & - & 30.3 & 2.0 & - \\
\hline $\operatorname{area}_{i, j, k} / A_{s}$ & $\%$ & - & 96.4 & - & 71.3 & 98.2 & - & 58.9 & 100.0 & - \\
\hline$q_{i, j, k}$ & $k W$ & - & 240.0 & - & 30.0 & 300.0 & - & 94.0 & 40.0 & - \\
\hline$r h_{i, j, k}$ & & - & 0.884 & - & 0.116 & 1.0 & - & 1.0 & 1.0 & - \\
\hline$r c_{i, j, k}$ & & - & 1.0 & - & 1.0 & 1.0 & - & & & - \\
\hline$t h_{i, k}$ & $K$ & - & 583.0 & - & 583.0 & 723.0 & - & 390.1 & 573.0 & - \\
\hline$t h_{i, k+1}^{i n}$ & $K$ & - & 390.1 & - & 390.1 & 573.0 & - & 323.0 & 553.0 & - \\
\hline$t h s_{i, j, k}$ & $K$ & - & 389.1 & - & 398.0 & 573.0 & - & 323.0 & 553.0 & - \\
\hline$t c_{j, k+1}$ & $K$ & - & 313.0 & - & 388.0 & 403.0 & - & 303.0 & 303.0 & - \\
\hline$t c_{j, k}$ & $K$ & - & 393.0 & - & 403.0 & 553.0 & - & 323.0 & 323.0 & - \\
\hline$t c s_{i, j, k}$ & $K$ & - & 393.0 & - & 403.0 & 553.0 & - & 323.0 & 323.0 & - \\
\hline \multicolumn{11}{|l|}{ Period 1} \\
\hline$A_{s}$ & $m^{2}$ & - & 22.4 & 9.4 & - & 25.0 & - & 51.4 & - & - \\
\hline $\operatorname{area}_{i, j, k}$ & $m^{2}$ & - & 22.4 & 9.4 & - & 25.0 & - & 45.4 & - & - \\
\hline $\operatorname{area}_{i, j, k} / A_{s}$ & $\%$ & - & 100.0 & 100.0 & - & 100.0 & - & 88.3 & - & - \\
\hline$q_{i, j, k}$ & $k W$ & - & 240.0 & 68.0 & - & 340.0 & - & 178.0 & - & - \\
\hline$r h_{i, j, k}$ & & - & 1.0 & 1.0 & - & 1.0 & - & 1.0 & - & - \\
\hline$r c_{i, j, k}$ & & - & 1.0 & 0.167 & - & 0.833 & - & & - & - \\
\hline$t h_{i, k}$ & $K$ & - & 555.2 & 593.0 & - & 723.0 & - & 421.9 & - & - \\
\hline$t h_{i, k+1}$ & $K$ & - & 421.9 & 555.2 & - & 553.0 & - & 323.0 & - & - \\
\hline$t h s_{i, j, k}$ & $K$ & - & 421.9 & 555.2 & - & 553.0 & - & 323.0 & - & - \\
\hline$t c_{j, k+1}$ & $K$ & - & 313.0 & 383.0 & - & 383.0 & - & 303.0 & - & - \\
\hline$t c_{j, k}$ & K & - & 393.0 & 553.0 & - & 553.0 & - & 323.0 & - & - \\
\hline $\begin{array}{l}t_{c S_{i, j, k}} \\
\text { Period } 2\end{array}$ & $K$ & \multicolumn{5}{|c|}{ Period 2} & - & 323.0 & - & - \\
\hline$A_{S}$ & $m^{2}$ & - & 25.0 & - & - & - & 22.4 & 51.4 & 9.4 & - \\
\hline $\operatorname{area}_{i, j, k}$ & $m^{2}$ & - & 17.4 & - & - & - & 17.2 & 51.4 & 4.0 & - \\
\hline $\operatorname{area}_{i, j, k} / A_{s}$ & $\%$ & - & 69.6 & - & - & - & 76.8 & 100.0 & 42.5 & - \\
\hline$q_{i, j, k}$ & $k W$ & - & 240.0 & - & - & - & 256.0 & 246.0 & 84.0 & - \\
\hline$r h_{i, j, k}$ & & - & 1.0 & - & - & - & 1.0 & 1.0 & 1.0 & - \\
\hline$r c_{i, j, k}$ & & - & 1.0 & - & - & - & 1.0 & & & - \\
\hline$t h_{i, k}^{i, n}$ & $K$ & - & 593.0 & - & - & - & 723.0 & 459.7 & 595.0 & - \\
\hline$t h_{i, k+1}^{l, n}$ & $K$ & - & 459.7 & - & - & - & 595.0 & 323.0 & 553.0 & - \\
\hline$t h s_{i, j, k}$ & $K$ & - & 459.7 & - & - & - & 595.0 & 323.0 & 553.0 & - \\
\hline$t c_{j, k+1}$ & $K$ & - & 313.0 & - & - & - & 393.0 & 303.0 & 303.0 & - \\
\hline$t c_{j, k}$ & $K$ & - & 393.0 & - & - & - & 553.0 & 323.0 & 323.0 & - \\
\hline$t c s_{i, j, k}$ & $K$ & - & 393.0 & - & - & - & 553.0 & 323.0 & 323.0 & - \\
\hline \multicolumn{11}{|l|}{ Period 3} \\
\hline$A_{s}$ & $m^{2}$ & 2.0 & 51.4 & 22.4 & - & 25.0 & - & - & - & 9.4 \\
\hline $\operatorname{area}_{i, j, k}$ & $m^{2}$ & 2.0 & 47.0 & 21.7 & - & 25.0 & - & - & - & 3.8 \\
\hline $\operatorname{area}_{i, j, k} / A_{s}$ & $\%$ & 100.0 & 91.4 & 96.9 & - & 100.0 & - & - & - & 40.4 \\
\hline$q_{i, j, k}$ & $k W$ & 27.4 & 154.5 & 68.0 & - & 340.0 & - & - & - & 58.0 \\
\hline$r h_{i, j, k}$ & & 0.443 & 1.0 & 0.557 & - & 1.0 & - & - & - & \\
\hline$r c_{i, j, k}$ & & 1.0 & 1.0 & 0.167 & - & 0.833 & - & - & - & 1.0 \\
\hline$t h_{i, k}$ & $K$ & 573.0 & 477.5 & 573.0 & - & 723.0 & - & - & - & 573.0 \\
\hline$t h_{i, k+1}$ & $K$ & 477.5 & 323.0 & 477.5 & - & 553.0 & - & - & - & 573.0 \\
\hline$t h s_{i, j, k}$ & $K$ & 511.0 & 323.0 & 450.9 & - & 553.0 & - & - & - & 573.0 \\
\hline$t c_{j, k+1}$ & $K$ & 364.5 & 313.0 & 383.0 & - & 383.0 & - & - & - & 373.7 \\
\hline$t c_{j, k}$ & $K$ & 373.7 & 364.5 & 553.0 & - & 553.0 & - & - & - & 393.0 \\
\hline$t c s_{i, j, k}$ & $K$ & 373.7 & 364.5 & 553.0 & - & 553.0 & - & - & - & 393.0 \\
\hline
\end{tabular}


1

2

3

4

5

6

7

8

9

10

11

12

13

14

15

16

17

18

19

20

21

22

23

24

25

26

27

28

29

30

31

32

33

34

35

36

37

38

39

40

41

42

43

44

45

46

47

48

49

50

51

52

53

54

55

56

57

58

59

60
Table 10 - Total annualized cost comparison for Example 3

\begin{tabular}{lc}
\hline & TAC (\$/yr) \\
\hline Floudas and Grossmann $^{10}$ & 49,879 \\
Chen and Hung $^{23}$ & 41,876 \\
Isafiade and Fraser $^{2 \prime}$ & 39,660 \\
Jiang and Chang & \\
This study & 37,787 \\
\hline
\end{tabular}


Abstract Graphic

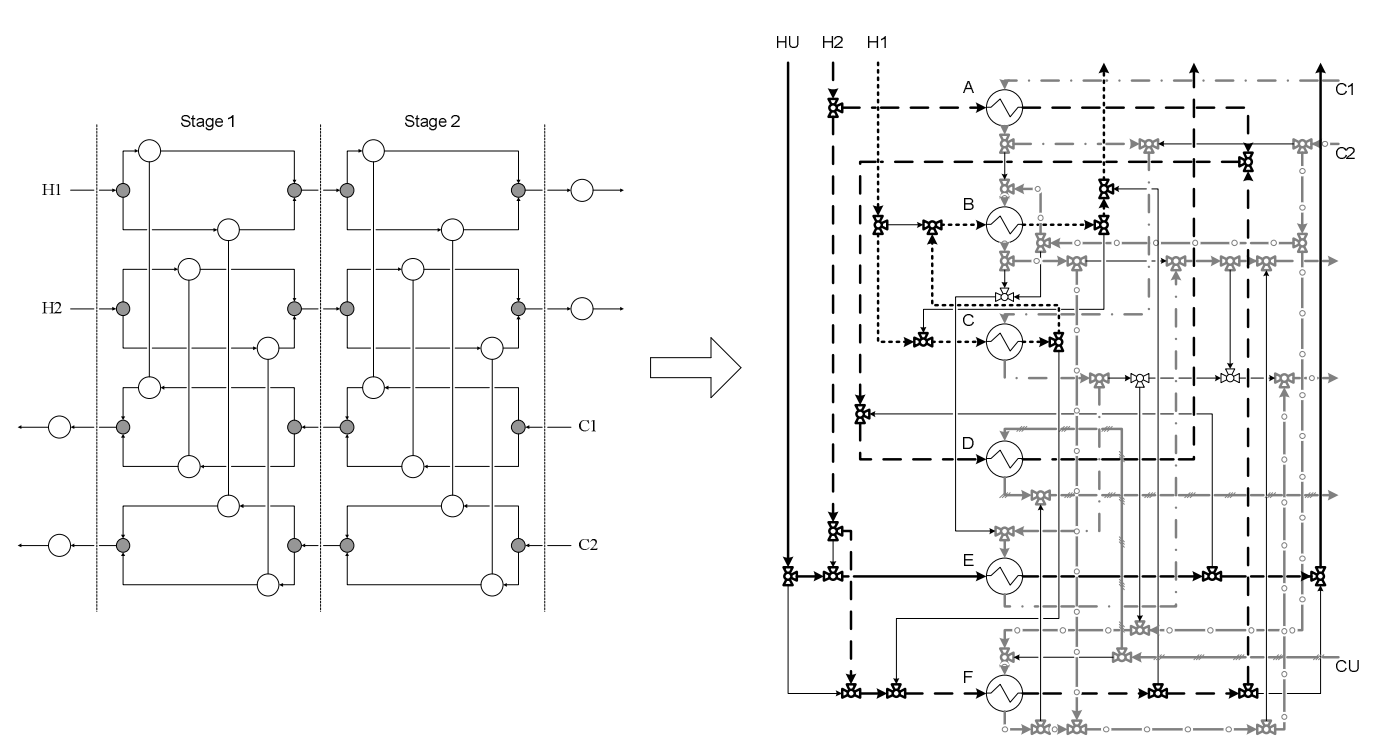

Abstract Graphic 